\title{
Corte de soporte o pilar sin gatos. Postesado para estructura metálica: Método cuña-contracuña; tecnología derivada
}

\author{
Removal of support or pier without jacks. Postensioned steel structure: \\ Wedge-chock method statement; derived technology
}

\author{
Jorge Aparicio García* \\ Dr. Ingeniero de Caminos, Canales y Puertos. INGETURARTE, S.L., Madrid, España
}

Recibido el 13 de febrero de 2018; aceptado el 3 de julio de 2018

\section{RESUMEN}

La supresión de soportes es una necesidad habitual cuando hay un cambio de uso arquitectónico o un cambio de luces en un puente. El presente documento plantea una solución de tecnología fácilmente accesible que permite definir un procedimiento de corte y puenteo de soporte sin la utilización de gatos. De esta obra surge una tecnología de postesado derivada para estructura metálica.

(C) 2018 Asociación Española de Ingeniería Estructural (ACHE). Publicado por Cinter Divulgación Técnica S.L.L. Todos los derechos reservados. PAlabras ClaVE: Supresión de soporte; Sin gatos; Postesado estructura metálica; Patente

\section{ABSTRACT}

The removal of supports is a common necessity when there is a change of architectural use or a span change in a bridge. The present document proposes a solution of easy technology that allows defining a procedure of cutting and bridging a support without the use of jacks. From this method statement arise a posttensioned technology for steel structure.

(C) 2018 Asociación Española de Ingeniería Estructural (ACHE). Published by Cinter Divulgación Técnica S.L.L. All rights reserved.

KEYWORDS: Removal of supports; Without jacks; Postensioned steel structure; Patent

1.

\section{INTRODUCCIÓN}

El presente artículo tiene como objeto describir un procedimiento constructivo para la supresión de soportes sin la utilización de gatos como medios auxiliares necesarios para la transferencia de cargas.

La técnica se presenta mediante el ejemplo concreto - y ejecutado- de supresión de soporte en vivienda unifamiliar.

El valor añadido del mismo es suministrar tecnología a los talleres de estructuras metálicas para facilitar un método de ejecución de corte de soportes y transferencia de cargas a estructura puente, asumible por los medios habituales en esta industria y sin la necesidad de industrias especialistas auxiliares adicionales.

El método es una variante adaptada de las formas de calzo provisionales de las grandes estructuras metálicas realizadas por MEGUSA, y esta idea en concreto plasma una de las muchas ideas que destila, sin quererlo, en cualquier conversación técnica D. Miguel Silvestre. Sin el precedente de la tecnología de la ampliación de luces de tableros de autovía de D. Julio Martínez Calzón y el equipo de MC2, este documento no hubiera sido posible; las cuestiones relativas al control y puesta en obra fueron desarrolladas con los ingenieros D. Abraham Hidalgo y D. Carles Cots Coromina; la visión innovadora, de atreverse a hacer algo nuevo, la aportó el jefe de obra; no me canso de agradecerles a todos.

* Correo electrónico: ingeturarte@telefonica.net 


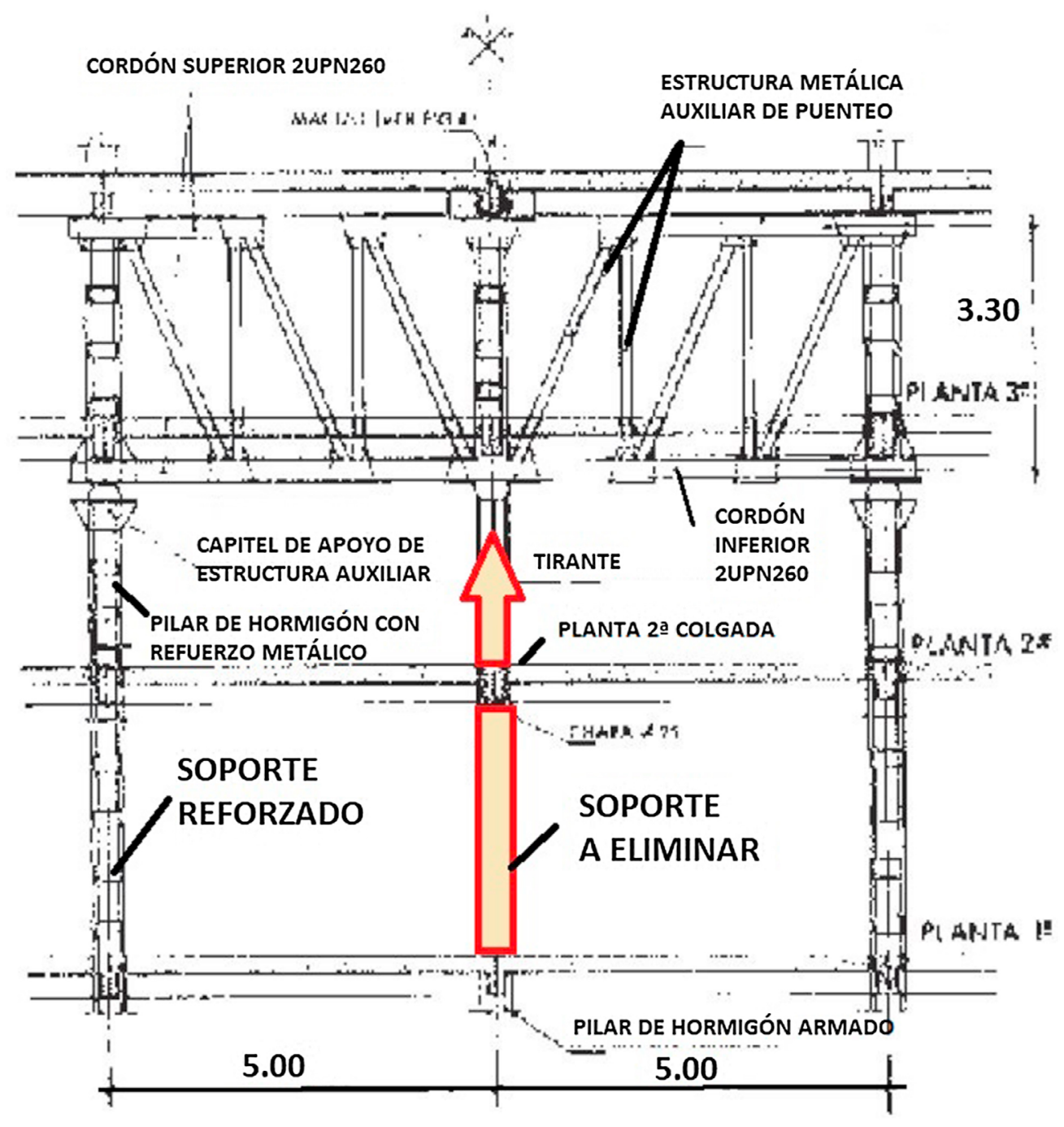

Figura 1. Supresión de pilar mediante estructura metálica.

2.

\section{SUPRESIÓN DE SOPORTES}

\subsection{La supresión de soportes: características estructurales- de la necesidad funcional}

El corte de soportes por cambio de uso tiene pocas características comunes y sistematizables, ya que depende de la tipología estructural, la propia geometría de la estructura y los nuevos requerimientos arquitectónicos y resistentes, lo que a su vez es específico de cada edificio y de cada estructura.

Por lo general, las cargas gravitatorias por encima del lugar del corte del soporte se trasladan a los pilares adyacentes a través de nuevas vigas puente. Esto implica ya sea reforzar dichos soportes adyacentes por el incremento de cargas y comprobar la cimentación existente - y reforzarla en caso de que no tenga suficiente capacidad portante-, ya sea adendar estructura auxiliar de puenteo de cargas o bien combinación de ambas.

En común a todos los procedimientos, se tiene la necesidad de disponer una estructura adicional, por lo general metálica [1] (fig. 1), pero también de hormigón armado [2], estructura mixta [3] (figs. 2 y 3) o de hormigón postesado [4] (fig. 4) que sirva para el puenteo de la cargas.

La estructura en la que se va a cortar el soporte suele tener recursos resistentes independientes para hacer frente a las solicitaciones horizontales, por lo que este importante requerimiento de la estructura en estado final se da por resuelto y no es objeto de este trabajo. Es decir, se va a proponer un método para la transferencia de cargas verticales.

Cuando la deformación de la nueva estructura puente está dentro de los rangos admisibles — es decir, apenas se deforma L/500 si se corta el soporte-, se puede hacer la transferencia de cargas de forma directa. Pero esto no es recomendable más que con cargas pequeñas; y es antieconómico para el coste de la estructura de refuerzo, ya que se necesita comprobar la flecha total como activa; esta metodología, como la que se propone en este artículo, también obvia la necesidad de realizar la transferencia de cargas mediante gatos. Adicionalmente, las posibilidades de dañar elementos arquitectónicos existentes en este caso es grande y han de acotarse y minimizarse, por lo que no se recomienda este procedimiento. 

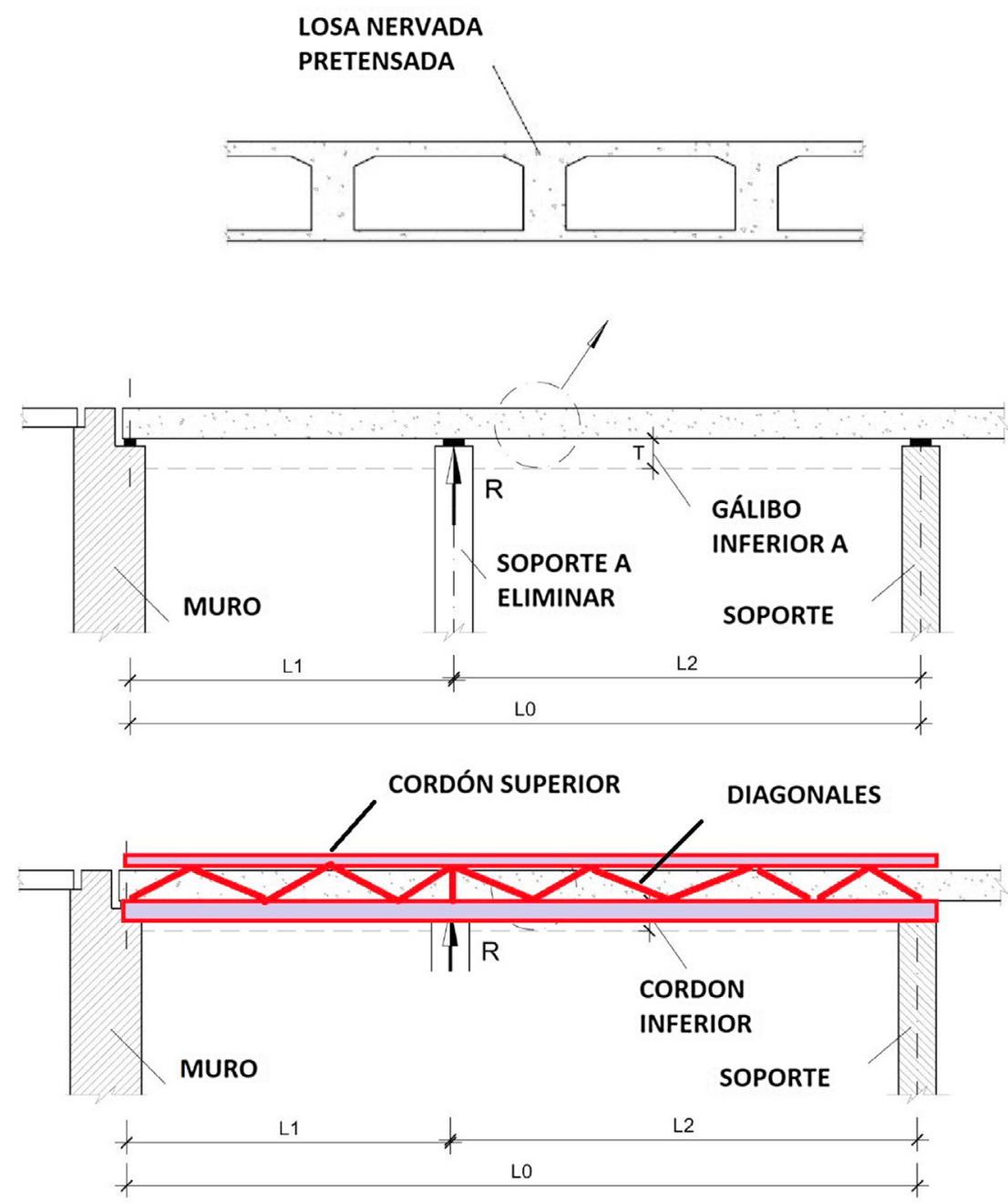

\begin{tabular}{|c|c|c|c|c|c|c|c|}
\hline DINTEL & $\begin{array}{c}\mathrm{L}_{0} \\
{[\mathrm{~m}]}\end{array}$ & $\begin{array}{c}\mathrm{L}_{1} \\
{[\mathrm{~m}]}\end{array}$ & $\begin{array}{c}\mathrm{L}_{2} \\
{[\mathrm{~m}]}\end{array}$ & $\begin{array}{c}\mathrm{T} \\
{[\mathrm{m}]}\end{array}$ & $\begin{array}{c}\mathrm{R}_{\text {cp. } \mathrm{k}} \\
{[\mathrm{kN}]}\end{array}$ & $\begin{array}{c}\mathrm{R}_{\text {sc., }} \\
{[\mathrm{kN}]}\end{array}$ & $\begin{array}{c}\mathrm{R}_{\text {totk }, k} \\
{[\mathrm{kN}]}\end{array}$ \\
\hline A & 33.40 & 20.40 & 13.00 & 0.80 & 5700 & 3700 & 9400 \\
\hline B & 34.85 & 25.80 & 9.05 & 0.80 & 8200 & 5400 & 13600 \\
\hline C & 32.25 & 14.80 & 17.45 & 2.00 & 6210 & 4050 & 10260 \\
\hline D & 28.65 & 13.10 & 15.55 & 2.00 & 5650 & 3700 & 9330 \\
\hline E & 30.35 & 16.70 & 13.65 & 2.00 & 6210 & 4050 & 10260 \\
\hline F & 27.10 & 15.80 & 11.30 & 2.00 & 5520 & 3600 & 9120 \\
\hline
\end{tabular}

Figura 2. Supresión de pilar mediante estructura mixta (1).

\subsection{Ejemplos de puenteo de cargas en obra civil}

Ejemplos de puenteo de cargas en obra civil que puedan servir de inspiración en el diseño del corte de soportes se encuentran en las metodologías de cambios de apoyos de puentes [5], donde las diferentes geometrías de estribos y pilas obligan a la rea- lización de prototipos de estructuras auxiliares para las maniobras de sustitución de apoyos, individuales para cada viaducto.

De especial interés es la solución de ampliación de luces de tableros de pasos superiores de autovía [6] (fig. 5), donde la aplicación que se presenta reconoce claro antecedente conceptual. 


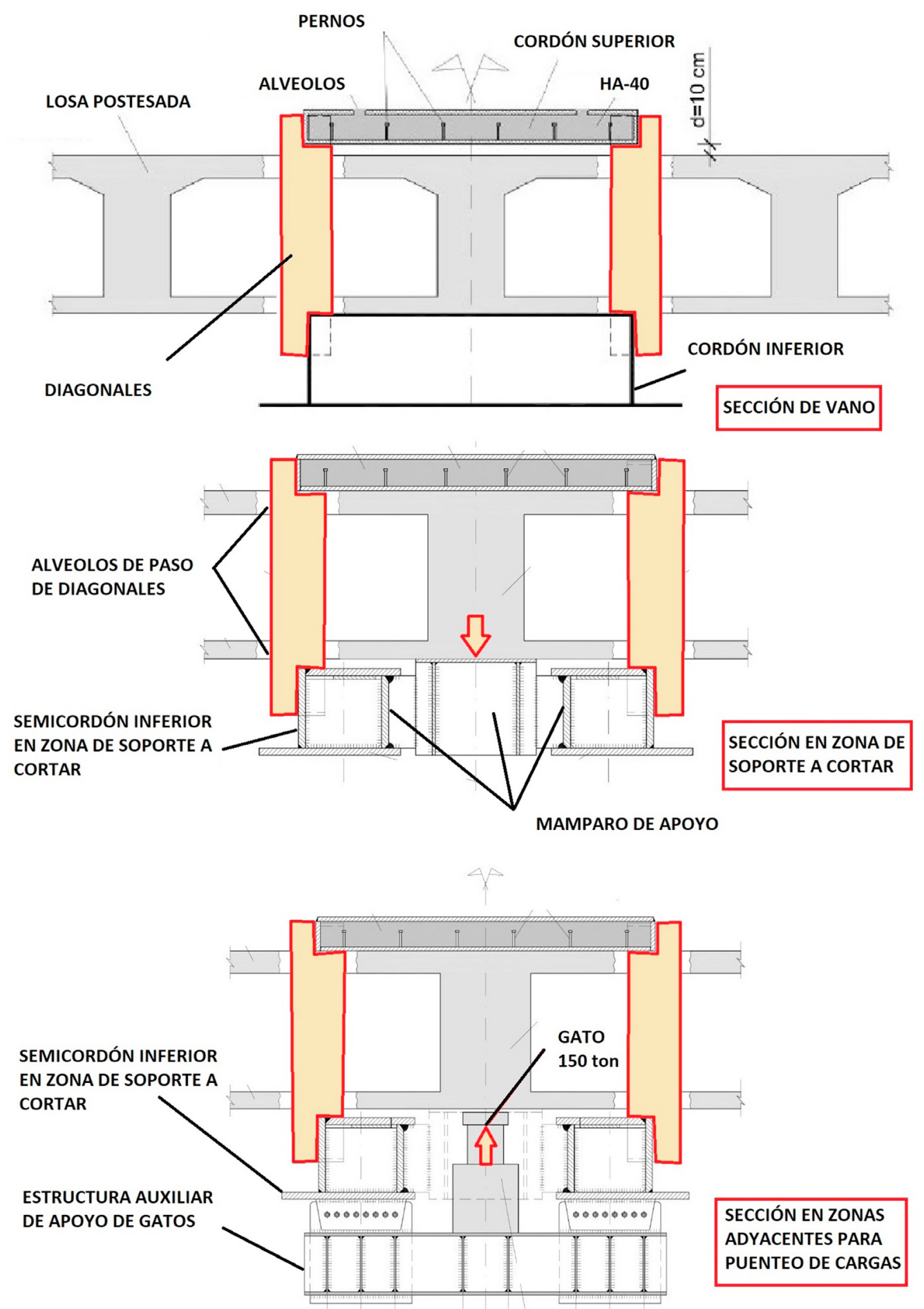

Figura 3. Supresión de pilar mediante estructura mixta (2).

3.

DESCRIPCIÓN DE LA OBRA Y DEL PROCEDIMIENTO CONSTRUCTIVO

\subsection{Descripción de la estructura y objeto de la actuación}

La tipología de la estructura del edificio, un chalet unifamiliar, se resume a continuación (fig. 6):

El forjado de primera es de vigueta y bovedilla cerámica de canto $12+5$ e intereje de $40 \mathrm{~cm}$.
Los soportes son de hormigón armado.

Las vigas descolgadas de $25 \mathrm{~cm}$ de canto también son de hormigón armado.

Las zapatas son pozos de cimentación cúbicos, de 1,10 m de lado, de hormigón en masa o de hormigón ciclópeo, aunque de las mediciones anteriores se infiere un lado de 1,26 m.

Se pretende la eliminación del soporte del medio del salón, tal y como se indica en la fig. 6. Se puentean $200 \mathrm{kN}$. 


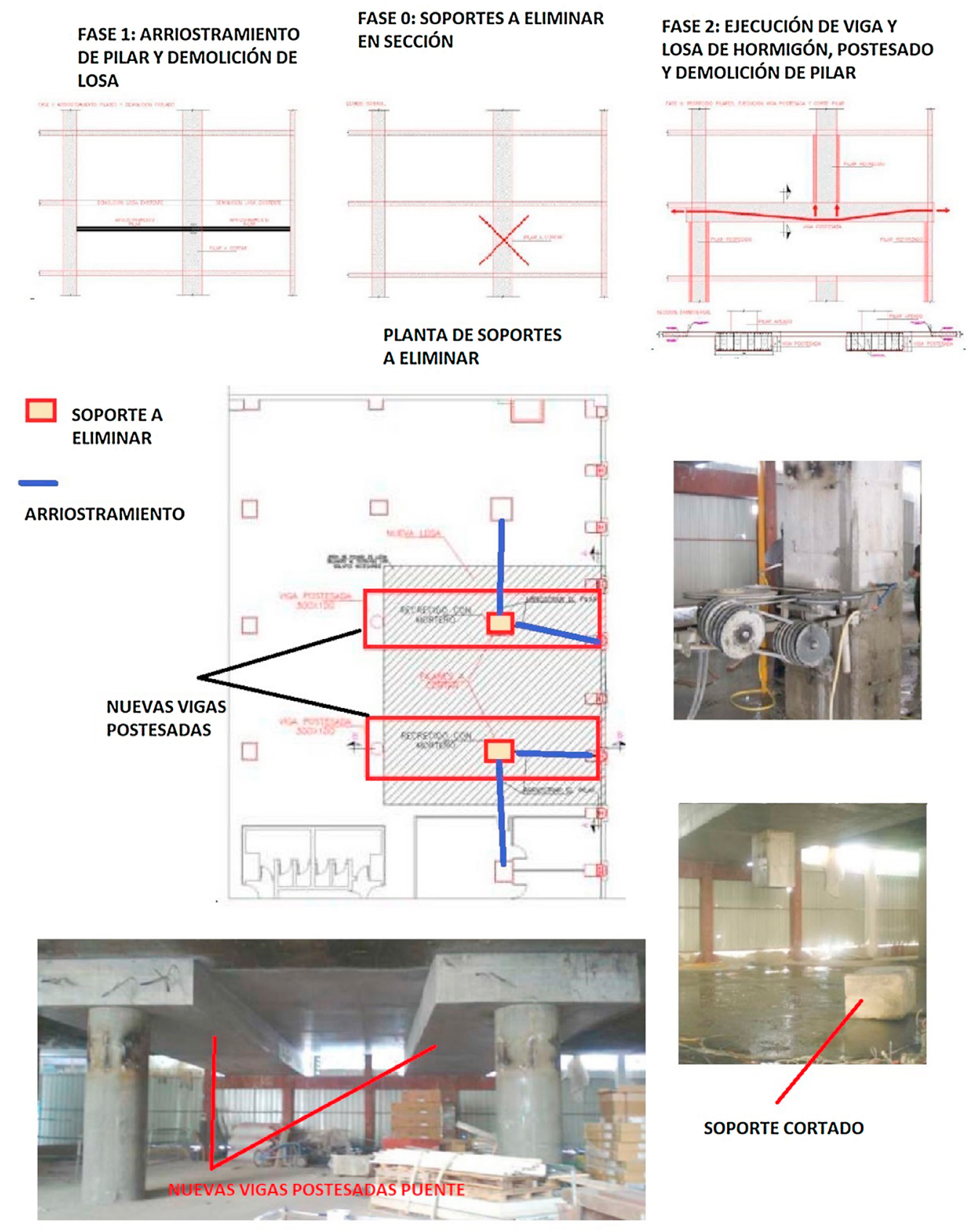

Figura 4. Supresión de pilar mediante estructura postesada.

\subsection{Criterios de proyecto}

A continuación se dan una serie de criterios apriorísticos con los que se debe proyectar la estructura de puenteo y los detalles de transferencia de cargas (fig. 7):

Las cargas muertas a disponer en solados, tabiques y falsos techos no se incrementan respecto de las soportadas en el histórico de la estructura.

Se propone la solución de mínimo coste posible.

Se acuerda el gálibo útil en el salón con la propiedad.

\subsection{Descripcion del procedimiento constructivo}

A continuación se describe telegráficamente el procedimiento constructivo, comenzando por la cimentación (fig. 8):
Se ejecuta la excavación para introducir la ferralla de la nueva viga de cimentación. La excavación tendrá $0,80 \mathrm{~m}$ de profundidad por $0,70 \mathrm{~m}$ de ancho, aproximadamente.

Se vierte un hormigón de limpieza de $0,10 \mathrm{~m}$.

Se introduce la nueva ferralla y se colocan las chapas de anclaje de los soportes.

Se hormigona la viga de cimentación con chapas de anclaje de soportes embebidas. Se procuran superficies rugosas limpias y humectadas entre hormigón de zapata y nuevo hormigón de cimentación. Si se realiza una comprobación por biela y tirante se justifica la solución a cortante.

A continuación se describen las fases del puenteo (fig. 9):

Se ejecuta un taladro en el soporte existente para la introducción de la barra galvanizada. La barra sirve para aplicar el par de apriete y poner en carga las cuñas. El taladro mínimo 


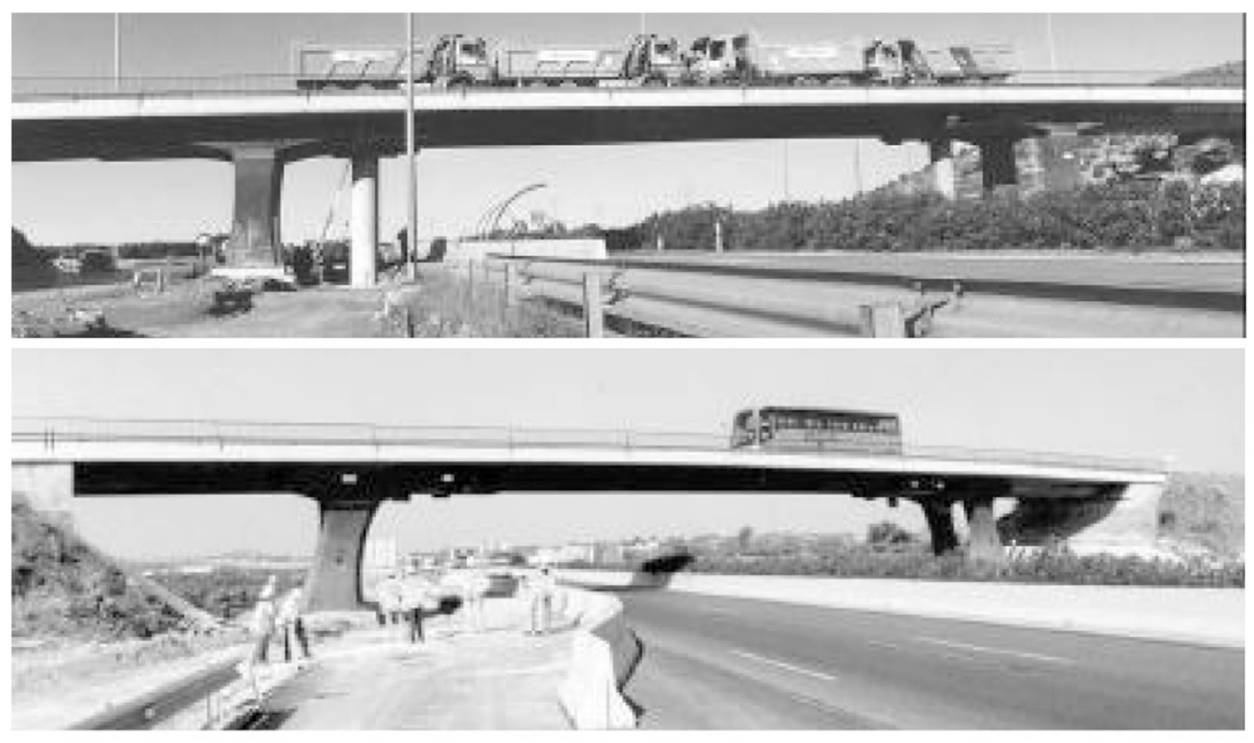

$31,00 \mathrm{~m}$

ESTADO INICLAL

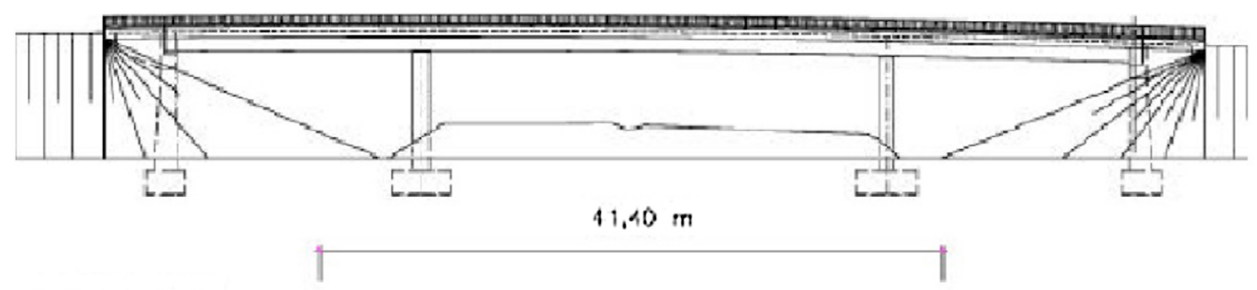

ESTADO FINAL

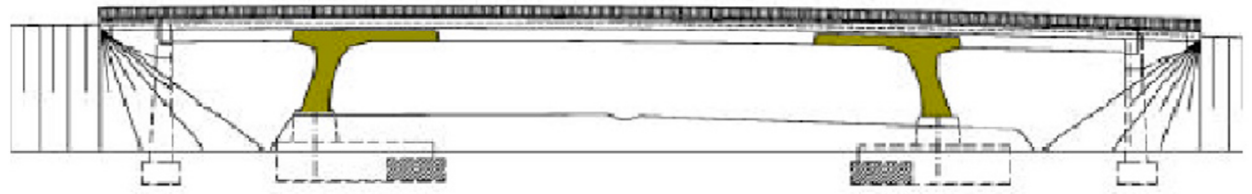

Figura 5. Supresión de pila de paso superior mediante estructura mixta.

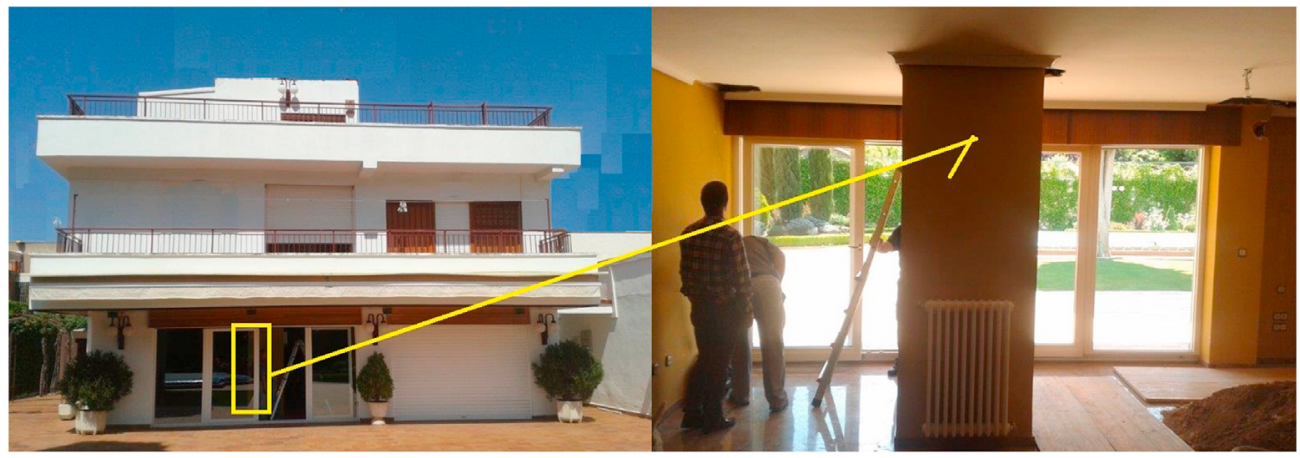

Figura 6. Edificio y localización del soporte a eliminar.

en soporte para enhebrar la barra es suficiente si se observa la cinemática de cuña contra mazarota, tal que permite desplazamientos relativos en las direcciones de los planos de contacto gracias a la aplicación de grasa en el mismo.

Se presentan las nuevas vigas metálicas en el suelo.

Se aploman y disponen los soportes UPE300 S275JR.

Se colocan las nuevas vigas UPE400 de acero S275JR a ambos lados del soporte de hormigón y apoyadas en ménsulas del soporte UPE300.

Se sueldan los puentes metálicos en forma de U invertida entre vigas armadas así como las soldaduras de soportes.

Se colocan a hueso las cuñas superiores (fig. 10).

Se pasa el tornillo de apriete de contracuñas inferiores por debajo de las cuñas superiores. 


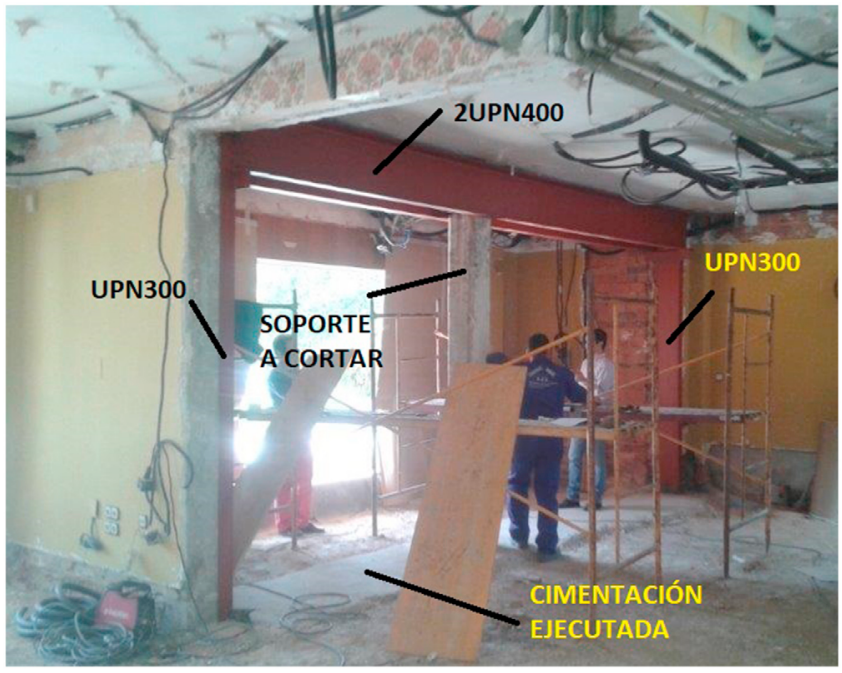

Figura 7. Estructura del puente antes de la operación de transferencia de cargasdel pilar a la viga metálica.

Se colocan las contracuñas inferiores.

Se hace penetración de las cuñas a través del apriete del tornillo por ambos lados hasta que el pilar entra en tracción.

El control del cambio de compresión a tracción fue acústico, ya que se puede saber por la variación del sonido del hormigón como si fuera una cerámica o un vidrio.

Se evita de esta manera la fisuración del hormigón del soporte bajo zona de puenteo, lo que provocaría a su vez una carga dinámica inversa no deseable para preservar acabados arquitectónicos existentes.

Cuando cambia el sonido del soporte, o cuando la cuña llegue a su tope estimado con base en los cálculos analíticos, se podrá cortar el soporte con medios adecuados —en ningún caso pica-pica o martilleo-. En concreto se utilizó una butronadora. Finas escayolas de la planta superior fueron preservadas, ahorrando su reparación.
Se sueldan los cordones de cierre protegiendo el tornillo y se disponen contratuercas para que no se desapriete el tornillo.

Se elimina el soporte restante y ya sin conexión.

\subsection{Criterios adicionales de importancia}

Las siguientes cuestiones se deben tener en cuenta desde el punto de vista técnico:

Se han de comprobar en obra las bondades de las hipótesis consideradas para el esbozo de solución, especialmente geometría.

Se recomienda la visita del técnico a obra para la revisión estructural en el momento de la ejecución del corte.

La supresión del pilar se realiza intentando que los elementos arquitectónicos en primera sufran el menor daño posible, aunque los techos de escayola de la zona afectada sufrirán desperfectos con casi total seguridad.

Queda una altura útil arquitectónica de 2,40 m entre la cara inferior de recubrimiento de viga y la cara superior de acabado arquitectónico, lo que hay que chequear seriamente, sobre todo para el paso de instalaciones por el falso techo.

La solución constructiva se estima con base en las cargas introducidas en un modelo espacial (fig. 11) del edificio entero, que aunque tiene serias incertidumbres de localización de soportes y vigas en la zona de eliminación del pilar, están estudiadas las cargas con suficiente aproximación.

Las cargas de diseño se basan en los acabados observados en obra, o en cota superior de los mismos.

Toda solución de rehabilitación estructural está sujeta a incertidumbres que deben minimizarse en proyecto pero que podrían necesitar de asistencia técnica a obra, por lo que debe preverse una partida para incertidumbres de forma que, si no se necesita, no se consume, pero no se crean problemas a las partes en caso de que sea necesaria más ingeniería y obra.

En el caso concreto presentado, se evita el realizar un geotécnico porque se conserva la forma estructural histórica

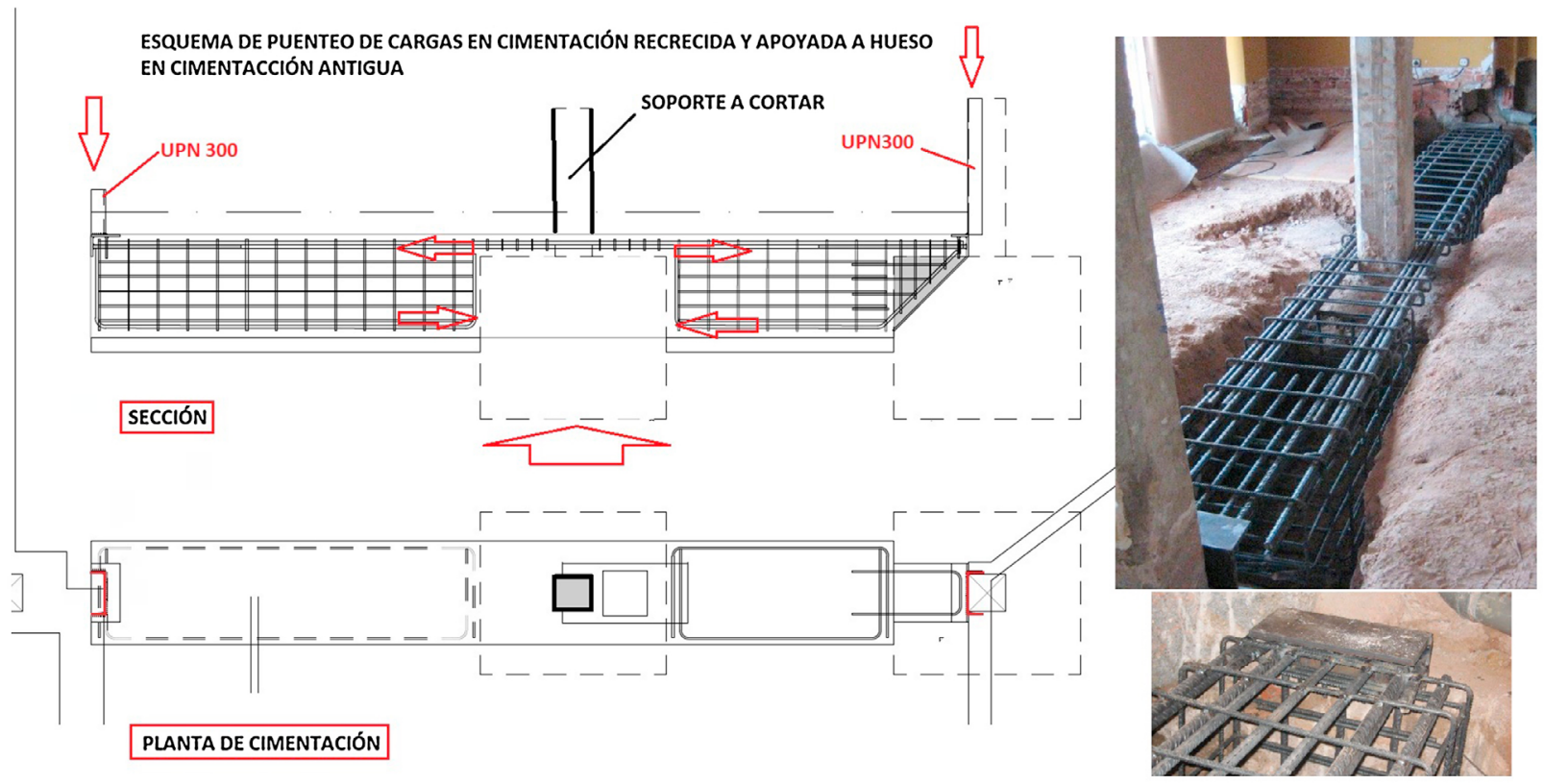

Figura 8. Esquema de cimentación puenteada. 


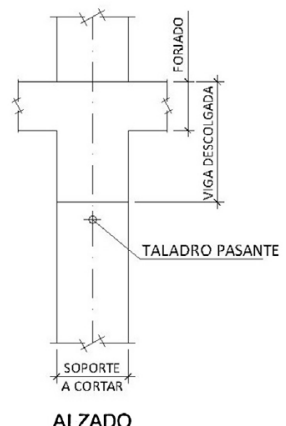

ALZADO

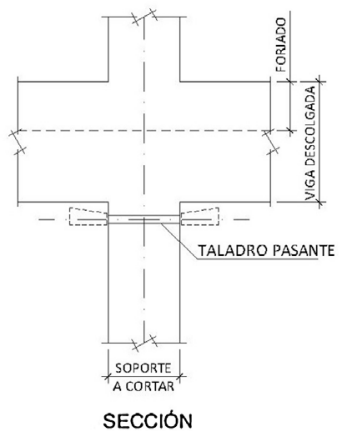

SECCIÓN

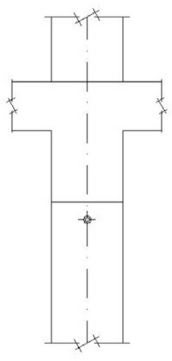

ALZADO

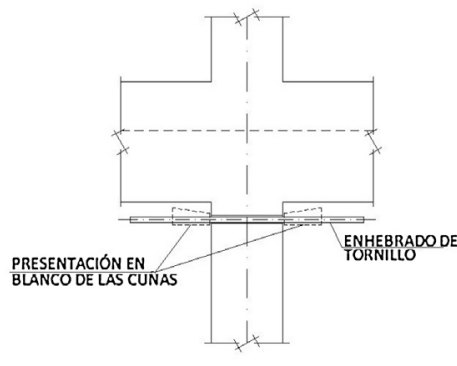

SECCION

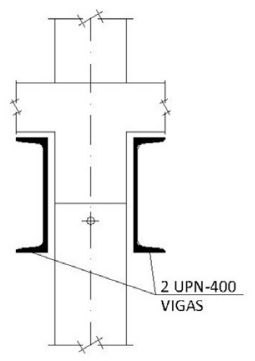

ALZADO

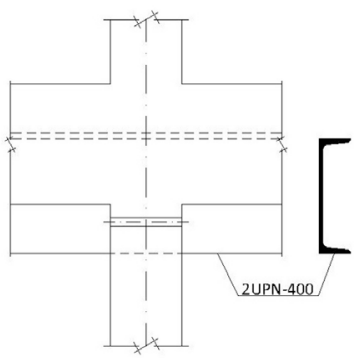

SECCIÓN

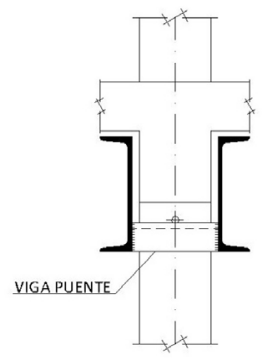

ALZADO

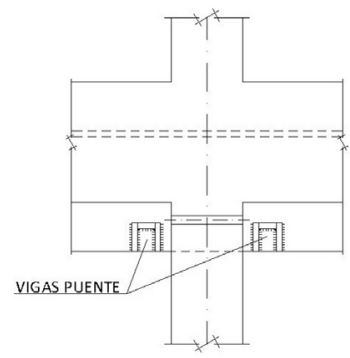

SECCION

FASE 3.2: APOYO A HUESO DE VIGAS A SOPORTES

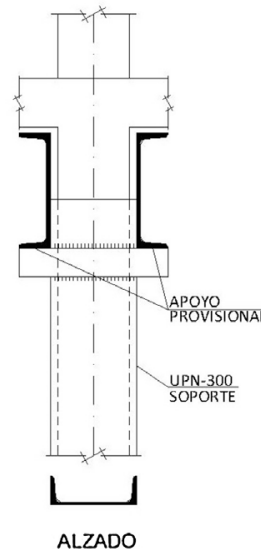

ALZADO
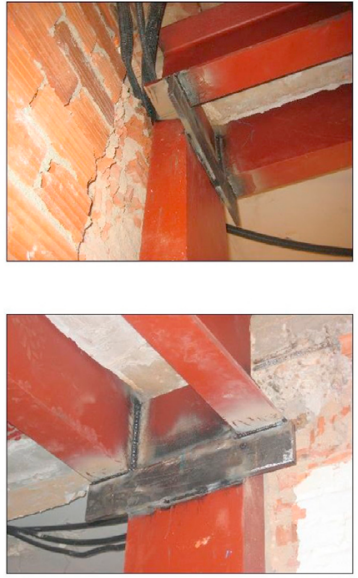

FASE 4.2: SOLDEO DE VIGAS A SOPORTES METÁLICOS

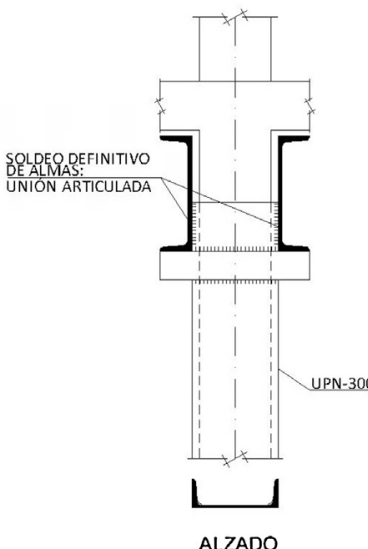

Figura 9. Procedimiento constructivo 1.

de recoger las cargas a través de una viga de cimentación que las lleva hasta la zapata original.

\subsection{Criterios de control y puesta en obra}

A continuación se enumeran cuestiones del control y puesta en obra de las operaciones (fig. 10):

Las contracuñas han de estar engrasadas en superficies de contacto con las cuñas y vigas puente para disminuir el rozamiento.
También se engrasarán las superficies en contacto entre tuercas y tornillo para disminuir el rozamiento y permitir el apriete mediante llave manual con palanca alargada por perfil tubular.

Antes y después del calce se debe proceder al control sónico del hormigón, es decir, como material cerámico; cuando está en compresión, el sonido es grave, y se vuelve más agudo al ponerse en tracción.

Con el ángulo agudo de $9^{\circ}$ para las cuñas definidas y grasa normal, el apriete se realiza por medios manuales, como se observa en la foto. 


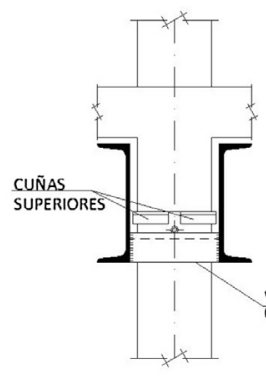

ALZADO

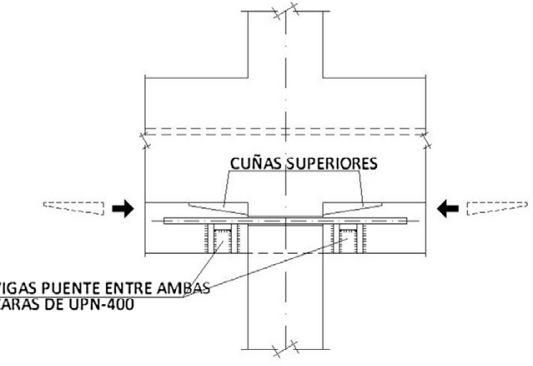

SECCIÓN

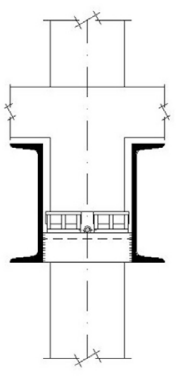

ALZADO

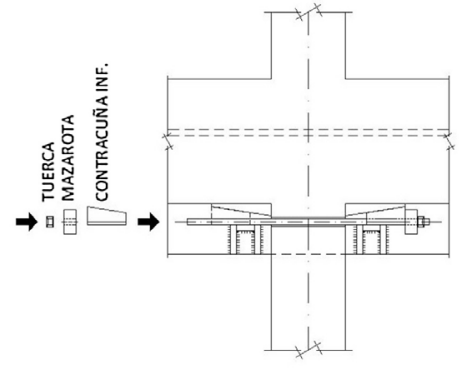

SECCIÓN
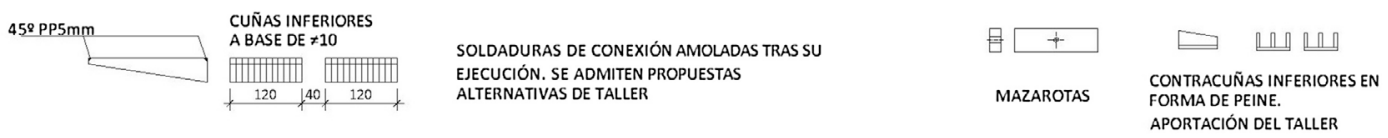

FASE 7: APRIETE HASTA DESCARGA DE SOPORTE Y CORTE

FASE 8: BUTRONADORA Y COLOCACIÓN DE CONTRATUERCAS

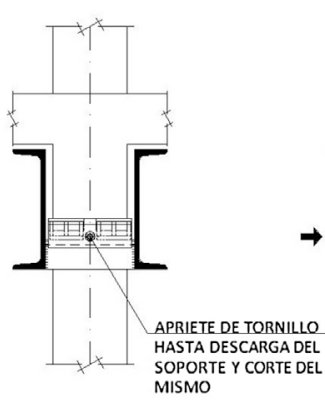

ALZADO

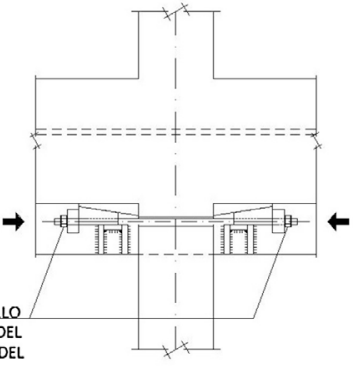

SECCIÓN
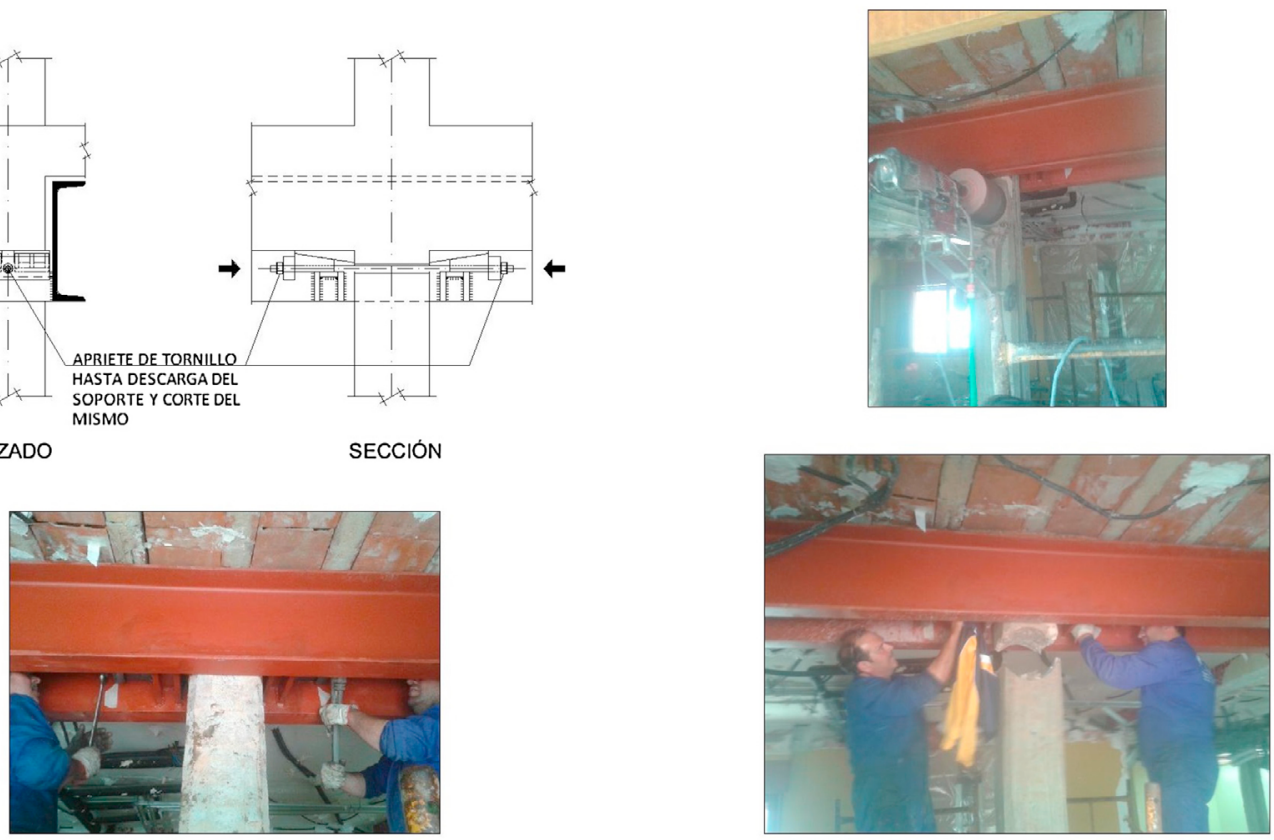

Figura 10. Procedimiento constructivo 2.

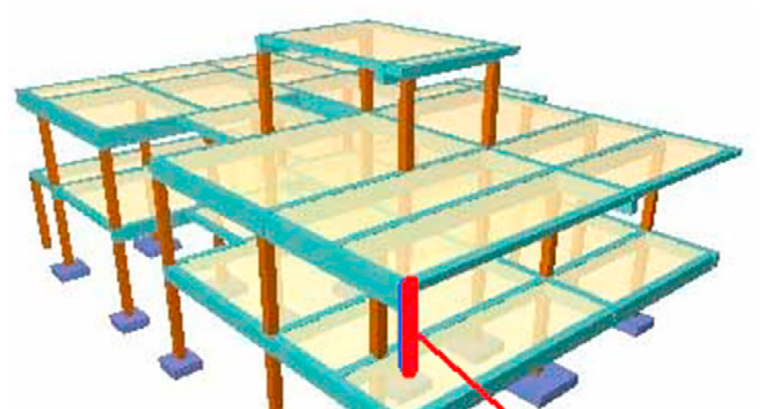

\begin{tabular}{|r|r|r|r|}
\hline \multicolumn{3}{|c|}{ BAIADA DE CARGAS DE SOP ORTE } \\
\hline REF & KN & KN & REF \\
\hline PP & 155 & & \\
\hline CM & 48 & 203 & $\mathrm{CP}$ \\
\hline SC & 48 & 48 & SC \\
\hline TOTAL & 251 & 251 & TOTAL \\
\hline
\end{tabular}

SOPORTE A ELIMINAR

Figura 11. Modelo de cálculo tridimensional para estimar las cargas a puentear. 

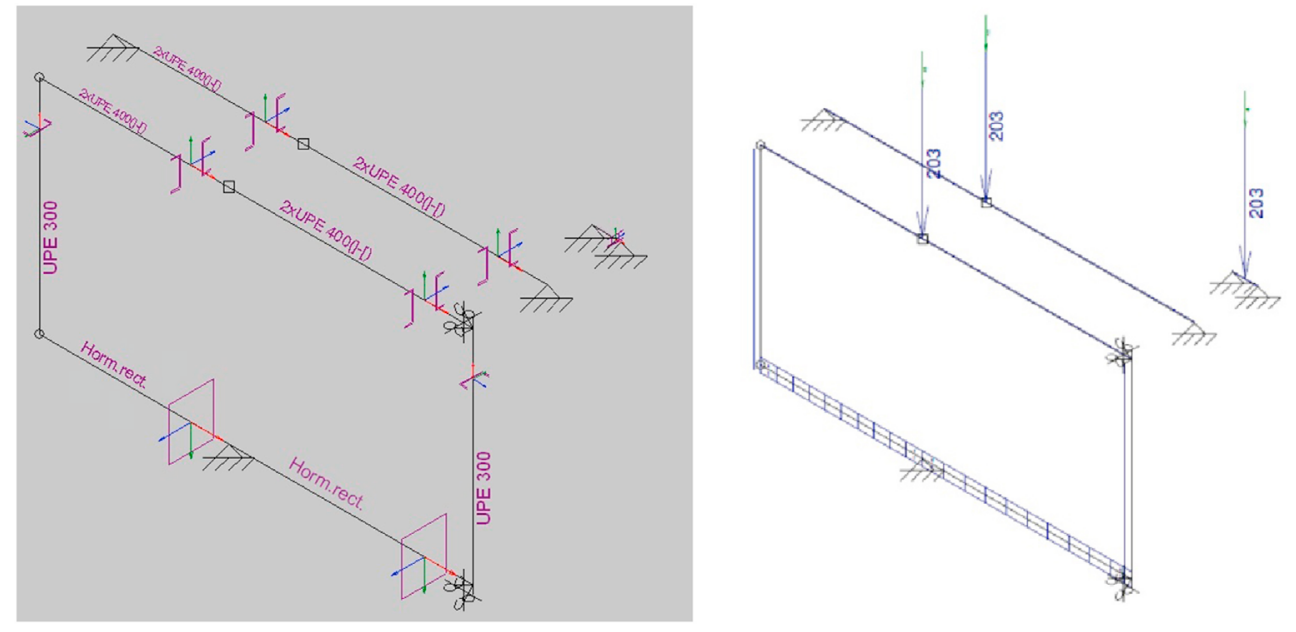

Figura 12. Modelo de cálculo de la estructura del puente.

Resaltar también que, para esa inclinación de $9^{\circ}$ de las cuñas, se demostró que el desapriete del tornillo conseguía hacer descender la estructura a su posición original. Lo que permite, una vez constatado el cambio sónico de la cerámica por el que se sabía del hormigón en tracción, ir aflojando para disminuir la fuerza vertical ascendente que pudiera transmitirse al cortar el soporte en tracción.

Como efecto colateral, la taladradora utilizada en el corte del pilar no sufre el aprisionamiento de la broca (de $220 \mathrm{~mm}$ de diámetro en nuestro caso) por efecto pinza de una parte del soporte contra la otra. En el caso presentado no fueron necesarios sobreesfuerzos para la retirada de la maquinaria, para sorpresa y celebración del personal de ejecución, que pudo irse antes a su casa.

Como método alternativo para el corte de pilar se preveía el roce circunferencial de dicho pilar para corte de armadura con radial, pero la taladradora se mostró eficaz para preservar integros todos los acabados arquitectónicos de primera.

Con un modelo de cálculo aproximado se estimó la carga permanente a puentear del soporte bajo primera a la nueva estructura metálica.

La estructura metálica, calculada como simplemente apoyada debido a la poca rigidez de los soportes, es muy noble y permite el control de la flecha a medida que se pone en carga la viga como mecanismo de control de la carga puenteada.

Para una flecha estimada de $10 \mathrm{~mm}$ se constató en obra una flecha de $8 \mathrm{~mm}$. Esta flecha se comprobó a un lado y a otro de la viga metálica midiendo el desplazamiento relativo entre el fondo de forjado y las alas superiores de vigas metálicas, dado que la carga se va transfiriendo desde el soporte como puntal hasta la viga metálica, sin desplazamiento del forjado. Para ello se utilizaron sencillas bandas de papel milimetrado.

También se controló el acortamiento de las cuñas, que se previó fuera de $13 \mathrm{~mm}$ y se midieron $10 \mathrm{~mm}$ cuando traccionaba el pilar.

\subsection{Descripción del cálculo}

Mediante un modelo de cálculo con el programa comercial METAL 3D de CYPE Ingenieros se realiza el siguiente mo- delo de cálculo (fig. 12), como el que se indica en la figura para la estructura metálica puente. Las cargas dispuestas son las obtenidas con el modelo tridimensional. El modelo supone que toda la carga descansa sobre la zapata existente (fig. 8):

En el modelo anterior se realizan dos hipótesis extremas, ambas del lado de la seguridad:

Una con el marco funcionando como tal y en el que la carga del peso propio de la riostra se recoge por el terreno -lo que en efecto es así-, y supone que las fuerzas horizontales (solo de compatibilidad) son recogidas por el forjado o por el soporte interior adyacente en su cabeza y llevadas a través del forjado a los cerramientos. Se supone que el resto de las cargas que vienen del soporte se absorben mediante el puenteo de la viga, que se apoya articuladamente en los soportes y descansa sobre la viga riostra en dos vuelos supuestos, lo que está del lado de la seguridad.

El otro modelo supone que la viga se apoya sobre los soportes de forma articulada y que estos no tienen descensos, porque el terreno es muy competente.

De esta manera se tienen cubiertos los dos extremos.

La flecha total en centro luz para la carga permanente está acotada entre los 10 y los $12 \mathrm{~mm}$, por lo que se diseñan las cuñas para la menor flecha entre ambas, dado que se desprecia el ligero empotramiento que seguro habrá entre soportes y vigas.

El aprovechamiento tensional del dintel llega al $77 \%$ como máximo, por lo que no se necesita refuerzo del mismo. El flector de diseño de la viga de cimentación es de 516 m.KN; el cortante de diseño es de $202 \mathrm{KN}$.

La tabla 1 se utiliza para armar la viga de cimentación.

Las vigas puente (fig. 13) se dimensionan para que solo una de ellas pueda soportar la totalidad de las cargas provenientes del soporte a cortar, lo que está del lado de la seguridad. La tabla 2 dimensiona dichas vigas.

Para el dimensionamiento de la geometría de la cuña y del tornillo a disponer para introducir dichas cuñas se utiliza la tabla 3, que comprueba la superficie de apoyo de las mencionadas cuñas en la parte inferior de viga, así como dimensiona el tornillo de postesado tipo barra Macalloy o similar que hará poner en carga la cuña y para la que sirve 
TABLA 1

Comprobación de la viga de cimentación.

\begin{tabular}{|c|c|c|c|c|}
\hline Ref. & Valor & UD & Fórmula & Descripción \\
\hline $\mathrm{Md}$ & 516 & KN.m & Del modelo de cálculo & Momento de diseño del modelo \\
\hline $\mathrm{b}$ & 0,60 & $\mathrm{~m}$ & & Ancho de viga \\
\hline c & 0,70 & $\mathrm{~m}$ & & Canto de viga \\
\hline $\mathrm{r}$ & 0,05 & $\mathrm{~m}$ & & Recubrimiento de viga \\
\hline d & 0,65 & $\mathrm{~m}$ & & Canto útil \\
\hline $\mathrm{z}$ & 0,585 & $\mathrm{~m}$ & & Brazo mecánico \\
\hline Us & 882 & $\mathrm{KN}$ & $\mathrm{Us}=\mathrm{Md} / \mathrm{z}$ & Capacidad a tracción a coser \\
\hline As & 20 & $\mathrm{~cm}^{2}$ & $\mathrm{As}=\mathrm{Us}^{*} 1,15 / 50$ & Área de acero necesaria \\
\hline f & 25 & $\mathrm{~mm}$ & & Diámetro de las barras a utilizar \\
\hline Af & 4,91 & $\mathrm{~cm}^{2}$ & Af $=\operatorname{PI}()^{*}(f / 20)^{2}$ & Área del redondo \\
\hline $\mathrm{nf}$ & 4,13 & $\mathrm{n} .{ }^{\circ}$ & $\mathrm{nf}=\mathrm{As} / \mathrm{Af}$ & Número de redondos necesarios \\
\hline $\mathrm{Vd}$ & 202 & $\mathrm{KN}$ & Del modelo de cálculo & Cortante de diseño \\
\hline Vcu & 195 & $\mathrm{KN}$ & & Cortante último \\
\hline Vsu & 7 & $\mathrm{KN}$ & & Cortante a recoger por la armadura \\
\hline Asv & 0,3 & $\mathrm{~cm}^{2}$ & & Armadura de corte necesaria \\
\hline$f_{\mathrm{v}}$ & 12 & $\mathrm{~mm}$ & & Área del redondo \\
\hline Arv & 1,13 & $\mathrm{~cm}^{2}$ & $\operatorname{Arv}=\operatorname{PI}()^{*}(\mathrm{fv} / 20)^{2}$ & Área del redondo \\
\hline $\mathrm{n}^{\circ} \mathrm{r}$ & 2 & $\mathrm{n}^{\circ}$ & & Número de ramas \\
\hline sv & 0,2 & $\mathrm{~m}$ & & Separación entre cercos \\
\hline Avd & 11,31 & $\mathrm{~cm}^{2}$ & & Armadura de corte dispuesta \\
\hline
\end{tabular}

un tornillo del 20, pero con gran recorrido de rosca. Esto es importante. La inclinación del plano de cuña es de $9^{\circ}$.

\subsection{Versionado de la aplicación práctica de puenteo de cargas descrita}

La solución práctica de puenteo de cargas descrita corresponde a una obra real en que la ingeniería costó más que la obra. Entre las aplicaciones prácticas múltiples que el proyectista puede concebir con esta nueva herramienta, que no es sino un procedimiento económico de transferencia lenta y controlada de cargas, estaría la versión 2.0 de ampliación de luces de tableros de autovía sin el empleo de estructura auxiliar (fig. 14), con lo que se llegaría al concepto puro de autogeneración estructural que ha promulgado D. Julio Martínez Calzón [7] y cuyo seguimiento implica mayor complejidad al proyectista, pero menor huella de carbono y mayor economía de obra.
4.

\section{NUEVA TIPOLOGÍA DE POSTESADO DERIVADA}

\subsection{Antecedentes históricos del postesado. Patentes de postesado}

En el momento de documentar los antecedentes históricos se localizó uno que describe, para el año 2004, el estado del arte de la tecnología de pretensado de forma clara y brillante por parte de D. Juan Ayats Calsat, coinventor de patentes (fig. 15) de postesado. Es por ello que en este apartado se remite a este documento abierto a su consulta en la red. Es de justicia destacar esta tesina realizada en la UPC [9], de recomendada lectura para cualquier técnico, ya sea docente, contratista, especialista o proyectista que esté involucrado en la materia por su gran capacidad de síntesis, de descripción gráfica y por conocer cómo se ejecutaron las estructuras que nos va a tocar manteter.
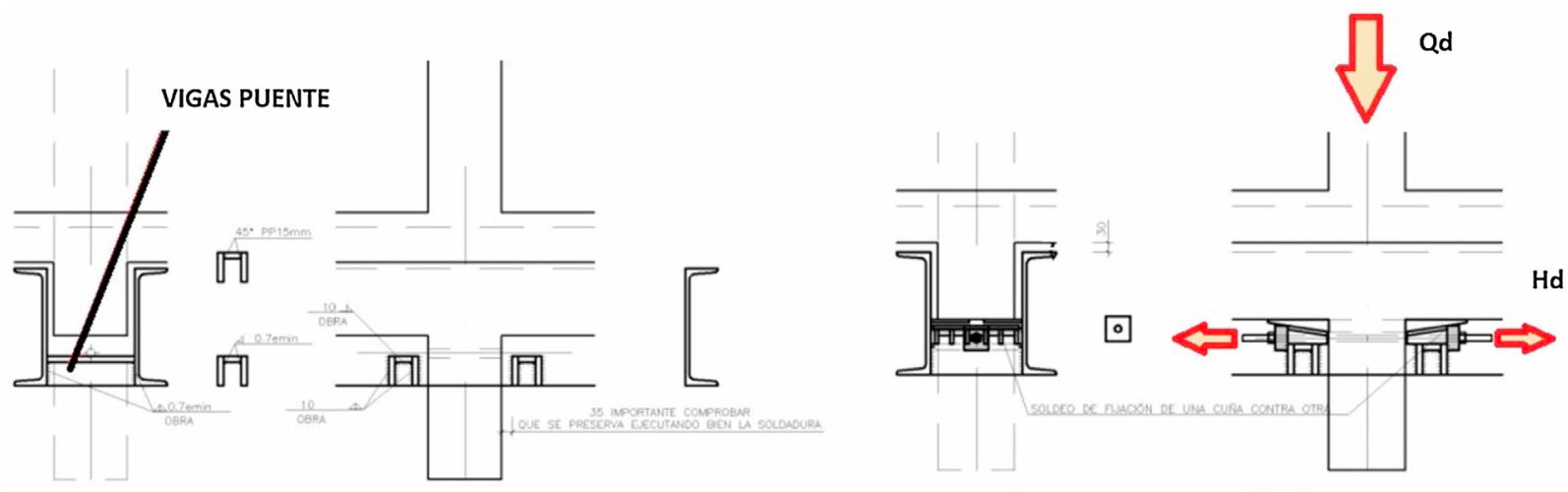

DIMENSIONAMIENTO DE LAS CUÑAS

Figura 13. Dimensionamiento de las vigas puente y de las cuñas. 
TABLA 2

Dimensionamiento de vigas puente.

\begin{tabular}{|c|c|c|c|c|}
\hline Ref. & Valor & UD & Fórmula & Descripción \\
\hline Qd & 353 & $\mathrm{KN}$ & & Carga mayorada de soporte \\
\hline $\mathrm{Vd}$ & 176,6 & $\mathrm{KN}$ & $\mathrm{Vd}=\mathrm{Qd} / 2$ & Cortante de diseño \\
\hline fyk & 27,5 & $\mathrm{KN} / \mathrm{cm}^{2}$ & & Resistencia característica a tracción del acero \\
\hline fyd & 25,0 & & fyd = fyk/1,1 & Resistencia minorada a tracción del acero \\
\hline tyd & 14,4 & & tyd $=\mathrm{fyd} / 3^{\wedge} 0,5$ & Resistencia minorada a cortante del acero \\
\hline Asv & 12,2 & $\mathrm{~cm}^{2}$ & Asv $=\mathrm{Vd} /$ tyd & Resistencia a corte necesaria \\
\hline a & 1 & $\mathrm{~cm}$ & & Garganta de soldadura \\
\hline $\mathrm{n}^{\circ} \mathrm{a}$ & 4 & n. ${ }^{\circ}$ & & Número de soldaduras verticales \\
\hline la & 6 & $\mathrm{~cm}$ & & la $=8-1-1$ longitud efectiva de soldadura a corte \\
\hline Asv disp & 24,0 & $\mathrm{~cm}^{2}$ & & Armadura a corte dispuesta \\
\hline
\end{tabular}

TABLA 3

Dimensionamiento de cuñas.

\begin{tabular}{|c|c|c|c|c|}
\hline Ref. & Valor & UD & Fórmula & Descripción \\
\hline Qd & 353 & $\mathrm{KN}$ & & Carga mayorada de soporte \\
\hline $\mathrm{Vd}$ & 176,6 & $\mathrm{KN}$ & $\mathrm{Vd}=\mathrm{Qd} / 2$ & Carga de cada cuña \\
\hline fck & 2,5 & $\mathrm{KN} / \mathrm{cm}^{2}$ & & Resistencia característica a tracción del hormigón \\
\hline fcd & 1,7 & $\mathrm{KN} / \mathrm{cm}^{2}$ & $\mathrm{fcd}=\mathrm{fck} / 1,5$ & esistencia minorada a tracción del hormigón \\
\hline Ac & 106,0 & $\mathrm{~cm}^{2}$ & $\mathrm{Ac}=\mathrm{Vd} / \mathrm{fcd}$ & Área de apoyo de cuña en hormigón \\
\hline Lc & 10,3 & $\mathrm{~cm}$ & $\mathrm{Lc}=\mathrm{Ac}^{\wedge} 0,5$ & Lado del cuadrado de apoyo mínimo \\
\hline a & 10 & $\mathrm{~cm}$ & & Lado de apoyo de un lado de la cuña \\
\hline $\mathrm{b}$ & 20 & $\mathrm{~cm}$ & & Lado de apoyo del otro lado de la cuña \\
\hline $\mathrm{n} \otimes$ & 2,0 & n. ${ }^{\circ}$ & & Número de cuñas por lado \\
\hline Ac disp & 400 & $\mathrm{~cm}^{2}$ & & Área de superficie de contacto \\
\hline tcd & 0,442 & $\mathrm{KN} / \mathrm{cm}^{2}$ & $\mathrm{tcd}=\mathrm{Bd} / \mathrm{Ac} \operatorname{disp}$ & Tensión mayorada en el hormigón de viga $<0,4 \mathrm{fck}$ \\
\hline $\mathrm{m}$ & 0,5 & - & & Coeficiente de rozamiento máximo entre aceros \\
\hline a & 9 & & & Ángulo de inclinación de cuña \\
\hline Hd & 232 & $\mathrm{KN}$ & $\mathrm{Hd}=\mathrm{m}^{*} \mathrm{Qd}+\mathrm{Qd}^{*} \operatorname{seno}(\mathrm{a})$ & fuerza máxima a hacer por el tornillo \\
\hline $\mathrm{Tu}$ & 323 & $\mathrm{KN}$ & $<\mathrm{Hd}$ & Tracción última según catálogo \\
\hline $\mathrm{Hd} / \mathrm{Tu}$ & 0,718 & 1,39 & $>1,35$ & Se garantiza el deslizamiento de cuñas \\
\hline
\end{tabular}

No obstante, se enumeran a continuación una serie de tecnologías de postesado, haciendo referencia a una fuente abierta de conocimiento muy poco habitual en las publicaciones técnicas de estructuras iberoamericanas, muy poco frecuentes en las fuentes de las tesis referentes a los temas de estructuras, pero fundamentales en cuanto a contenido de conocimiento para quien quiera ampliar el dominio de la técnica: las patentes.

El estudio y el conocimiento de las patentes de ingeniería civil era, sin embargo, una preocupación de nuestros actuales mayores, como refleja el artículo del Instituto de la Construcción de esta publicación [10], que no es sino una traducción parcial de una referencia norteamericana [11] que estudia más de 100 patentes relativas al pretensado.

Se enumeran las siguientes características de las patentes: primero, son públicas, luego son una fuente de conocimiento abierto y universal; segundo, son un honesto esfuerzo que ofrece un grupo de personas que considera que ha desarrollado una invención con valor y con la intención de obtener un retorno; tercero, se utilizan para honesta defensa del conoci- miento industrial; cuarto, son independientes, al estar sancionadas por la comunidad científica internacional, por lo que se consiguen en honesta competencia, algo difícil de lograr en el mundo en que nos movemos.

En cuanto a los sistemas de postesado, se pueden tomar en consideración los siguientes, patentados hasta 1964 (fig. 16), extractados de la tesina [9] antes mencionada, y de los que solo uno es iberoamericano.

De entre los enumerados anteriormente, solo algunos subsisten, y de entre los que subsisten, todos sin excepción vinculan la explotación del producto a la protección del conocimiento vía patentes, o a la explotación de patentes caducadas.

Se quiere rescatar expresamente la patente española regalada a la comunidad técnica por D. Antonio Angulo Ávarez, presidente durante muchos años de la Asociación de Amigos del Autogiro [12] y descrita en la revista de obras públicas [13]. Esta patente (fig. 17) no está recogida en el cuadro anterior.

Si el sistema de tesado mediante gatos de esta patente Angulo Álvarez se cambia por el sistema de tesado me- 


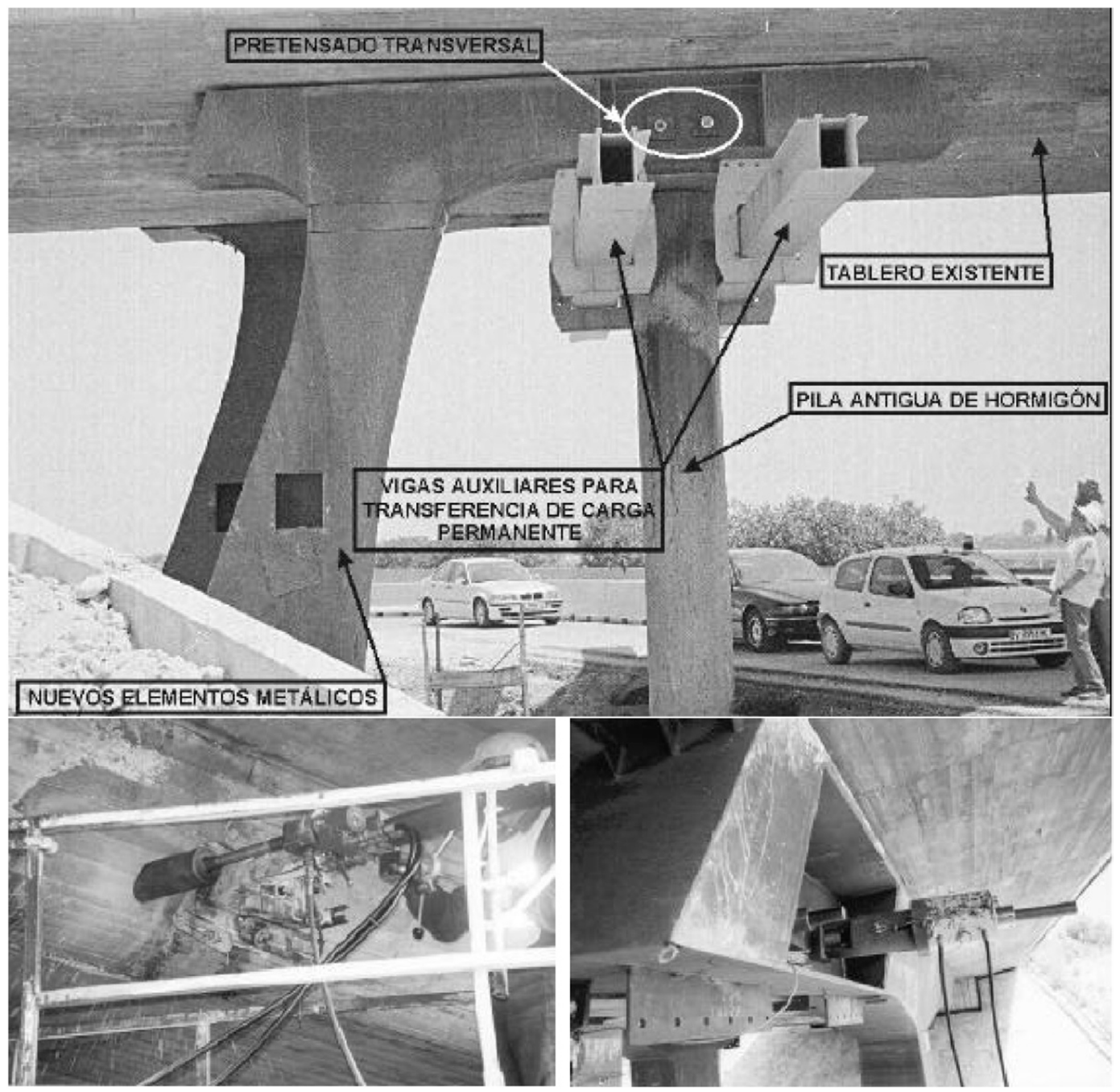

Figura 14. Solución de ampliaciones de luces 1.0.

diante cuña y contracuña, enhebrando a posteriori la misma chapa-calzo en forma de $U$ y convenientemente adaptado y diseñado en espesores de chapas, se puede recuperar esta aplicación.

La principal ventaja del método de cuña y contracuña para tesado de barras es la posibilidad de realizar la operación de tesado mediante la aplicación de fuerzas transversales para lograr así el postesado longitudinal, lo que puede ser adecuado cuando no haya espacio para colocar los gatos de tesado en la posición longitudinal de las barras. También se evitan los gatos planos.

Como muestra del desarrollo que tiene este detalle de tecnología de cuñas y contracuñas se ha encontrado la patente [14] de la fig. 18, que sirve para garantizar la transmisión de la compresión de barras y evitar el desapriete, que imaginamos tendrá su aplicación en estructuras off-shore.

\subsection{El postesado como equipamiento estructural de gran valor añadido}

Los ahorros que se pueden conseguir en las obras civiles utilizando pretensados o postesados son de todos conocidos.
Esta tecnología es dominada por los ingenieros estructurales de todo el mundo, siendo especialmente desarrollada en la Europa continental, Estados Unidos y Japón.

Es un hecho que en estos países, cuando terminaron de construir sus infraestructuras, todo el esfuerzo realizado en la producción de las mismas se procuró fijar en patrimonio empresarial e industrial — por ese orden — tal que permitiera el mantenimiento en dichas infraestructuras construidas y la exportación de las tecnologías desarrolladas donde eran necesarias, de forma que se mantuviera el know-how, el saber-cómo.

Históricamente, en Iberoamérica la transferencia del conocimiento inventivo en empresas e industria siempre ha sido difícil. El caso de D. Isaac Peral [15] con el submarino y el de D. Juan de la Cierva con el autogiro [16] son los ejemplos más notorios de pérdidas de oportunidad de creación de riqueza industrial. Como escribió el filósofo hispanoamericano [17], «aquellos que no recuerdan el pasado están condenados a repetirlo», y como decía el profesor de filosofía D. Jean-Philibert Damiron [18], «conocerse para corregirse».

En casi todas las geografías del planeta se puede ver un puente con una solución atirantada, pero no todos los países pueden tener una industria que suministre los tirantes. 


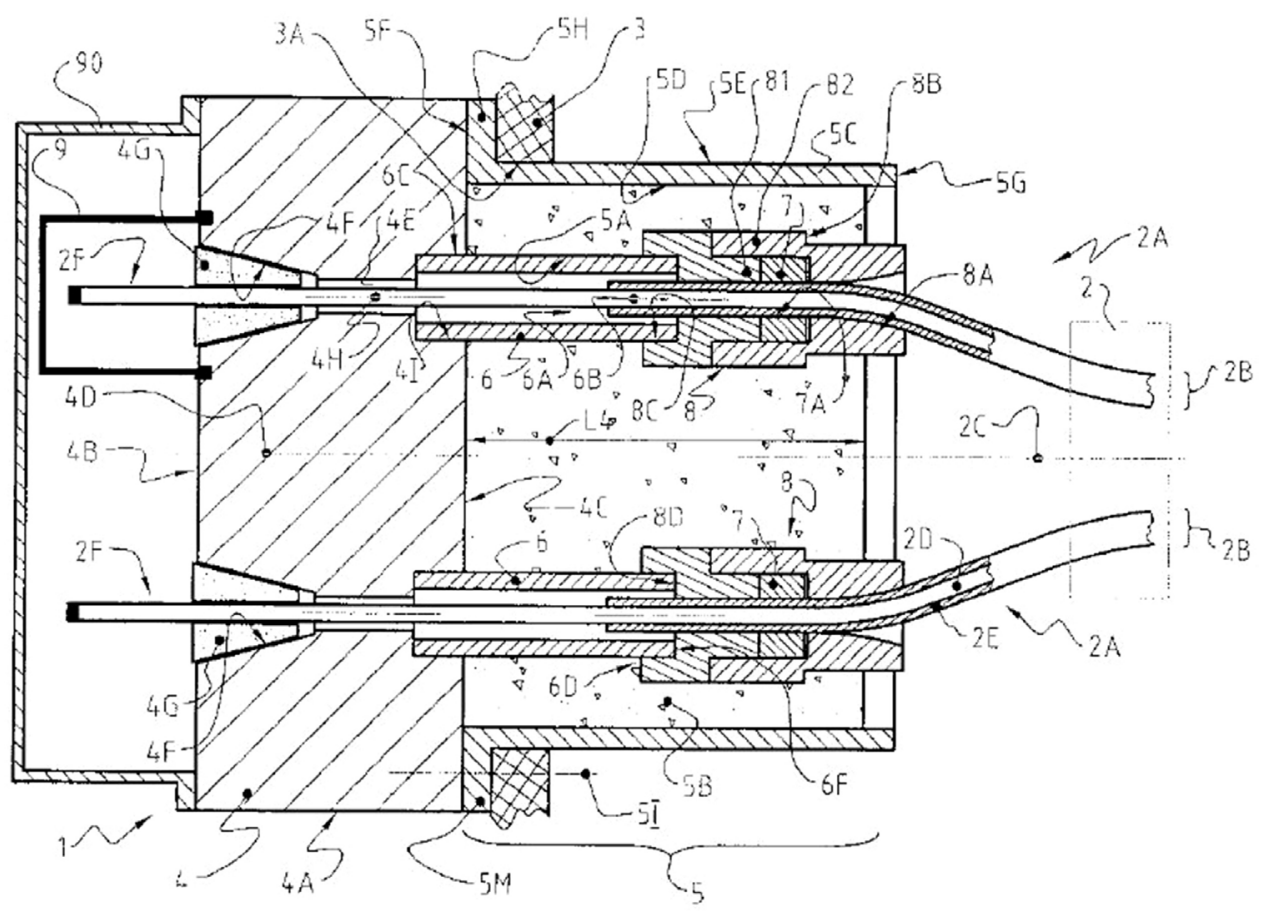

Figura 15. Tecnología perteneciente a VSL.

Todas las empresas punteras de suministro del postesado han continuado desarrollando la curva de aprendizaje de la técnica y protegiendo sus avances mediante patentes y/o know-how, saber cómo.

Así la herencia de D. Eugène Freyssinet, primero patentando la técnica del cómo pretensar en Francia [19] y más tarde en Estados Unidos [20] (fig. 19) es especialmente modélica, donde la empresa constructora [21] que se creó en 1943 para el suministro de los servicios de postesado ha crecido dando un gran valor añadido a la empresa y a la industria de la construcción, y a la sociedad donde ha suministrado los servicios y donde ha creado empleo en más de 70 países. Por poner un ejemplo paradigmático del empleo del postesado, toda la industria francesa de generación eléctrica con combustible nuclear está apoyada en la tecnología del postesado como parte fundamental de su obra civil. Un grand héritage.

Los desarrollos industriales suizos y alemanes son también de especial relevancia, donde empresas suizas como BBR [22], fundada en 1944 por D. Max Birkenmaier, D. Antonio Brandestini y D. Mirko Robin Ros, que introdujo su tecnología de postesado en España en 1963 y sigue introduciéndolo y protegiendo sus mejoras [23]; y VSL [24], fundada en 1943, época en la que fueron protagonistas D. Hans Dietrich, inventor del sistema de torones, D. Hans Elsässer, gerente especial de métodos constructivos, y el vicegerente D. Giovanni Crivelli. La alemana DYWIDAG [25] desarrolla con D. Franz Dischinguer los primeros sistemas de postesado en 1925-1927, y comienza a licenciar las patentes francesas a partir de 1950.

Países latinos del sur también tienen sus desarrollos industriales de postesado, como Portugal, con la empresa, desaparecida con la crisis, ICQ MANUEL ALVES; o España, con TECPRESA, heredera de las patentes de 1958 de D. Ricardo Barredo de Valenzuela [26], verdadero precursor de la téc- nica del cómo pretensar industrial (fig. 20) en España, ya que permitió la generación de la industria que suministró y desarrolló [27] el producto. También MEKANO4 [28] desarrolla, desde hace más de 25 años, una gran actividad de postesado basada en un serio programa de desarrollo del know-how.

En Italia, TENSACCIAI [29], empresa creada en 1951, también ha desarrollado una industria del postesado, fundamentalmente a partir de 1964 .

\subsection{Volviendo a los orígenes: el primer sistema de poste- sado}

Volviendo a los orígenes, como en el caso del submarino y el autogiro, el primer sistema de pretensado ejecutado fue iberoamericano: en el acueducto de Tempull (fig. 21). En contra de lo que les sucedía a los autores de los hitos anteriores, el inventor no creía en el método del pretensado, o comenzó a creer tardíamente.

Buceando en los archivos del CHEOPU [30], gracias a la excelente divulgación técnica del portal web ESTRUCTURANDO [31], en un artículo — publicado en la revista Concret Travaux y que el autor no ha podido encontrarmecanografiado y perteneciente al archivo Torroja se extracta la siguiente nota relativa al acueducto de Alloz (fig. 21): «La técnica española ha utilizado diferentes veces los cables trenzados de acero de alta calidad, como armaduras pretensadas, en el hormigón armado. El primer ejemplo fue el utilizado por el Prof. Torroja en el acueducto de Tempull en 1926 [32], el cual ha empleado con éxito el mismo sistema en el acueducto de Alloz [33] en 1939.

Del párrafo anterior se infiere que se ha empleado el mismo sistema de postesado en ambos acueductos, pero cuando los comparas a simple vista, ¿dónde está el mismo sistema? 


\begin{tabular}{|c|c|c|c|c|c|}
\hline No. & Sistema & Pais de origen & Fuera (1) & Composición & (2) \\
\hline 1 & Anderson & USA & $\mathrm{m} \cdot \mathrm{g}$ & corcones & todos \\
\hline 2 & Barredo & España & $p$ & alambres & 3 \\
\hline 3 & Baur-Leonhardt & Alemania & G & alambres & tootos \\
\hline 4 & $\begin{array}{c}\text { Baur-Leonhardt y } \\
\text { Grün-Bilfinger }\end{array}$ & Alemania & G & alambres & todos \\
\hline 5 & Bauwens & Alemania & $p$ & alambres & - \\
\hline 8 & BBRV & Suiza & $\mathrm{m}, \mathrm{g}$ & alambres & todos \\
\hline 7 & Beton und Monierbau & Alemania & $\mathrm{m} . \mathrm{g}$ & alambres & todos \\
\hline 8 & Billner & USA & $m$ & alambres & todos \\
\hline 9 & Braunbock & Austria & todas & alambres & todos \\
\hline 10 & CCL 1 & Gran Breiaña & p. $m$ & alambres & 1 \\
\hline 11 & $\mathrm{CCL} 2$ & Gran Bretaña & $m$ & alambres & $\mathbf{i}$ \\
\hline 12 & CCL 3 & Gran Bretaña & $\mathrm{m}, \mathrm{g}$ & corcones & 1 \\
\hline 13 & Chalos & Francia & $\mathrm{m} \cdot \mathrm{g}$ & corcones & todos \\
\hline 14 & Coyne & Francia & $G$ & alambres & todos \\
\hline 15 & Crom & USA & $\mathrm{m}$ & alambres & $i$ \\
\hline i6 & DDR & Alemania & m & alambres & todos \\
\hline 17 & Dywidag & Alemania & m.g. G & barras & 1 \\
\hline 18 & Franki-Smet 1 & BElgica & $\mathrm{m}$ & alambres & todos \\
\hline 19 & Franki-Smet 2 & Besigica & $m$ & alambres & $i$ \\
\hline 20 & Freyssinet 1 & Francia & $m$ & alambres & todos \\
\hline 21 & Freyssinet 2 & Francia & $g$ & corcones & todos \\
\hline 22 & Grün \& Bilfinger & Alemania & $m$ & alambres & todos \\
\hline 23 & Guifford-Burrow & Gran Bretaña & $\mathrm{m}, \mathrm{g}$ & cordones & 1 \\
\hline 24 & Guifford-Udall & Gran Bretaña & p. m & alambres & 1 \\
\hline 25 & H.G. (Holzmann) & Alemania & $\mathrm{m}$ & alambres & todos \\
\hline 28 & Hauser & Italia & $p$ & alambres & $2-4$ \\
\hline 27 & Heilitbau & Alemania & m. & alambres & $i$ \\
\hline 28 & Held \& Franke 1 & Alemania & $\mathrm{m}$ & alambres & todos \\
\hline 29 & Held \& Franke 2 & Alemania & $m$ & barras & 1 \\
\hline 30 & Hochtiefbau & Alemania & $\mathrm{m}$ & alambres & todos \\
\hline 31 & Holzmann-Zerna & Alemania & $\mathrm{m} \cdot \mathrm{g}$ & alambres & todos \\
\hline 32 & Intemational Raymond & USA & $m$ & alambres & todos \\
\hline 33 & K.A. (lnterspan) & Alemania & $\mathrm{m}, \mathrm{g}$ & alambres & todos \\
\hline 34 & Kani-Barasel & Alemania & $\mathrm{m} . \mathrm{g}$ & alambres & todos \\
\hline 35 & Korowkin & URSS & $g$ & alambres & todos \\
\hline 36 & Kübler & Alemania & p. $m$ & alambres & todos \\
\hline $3 i$ & Kübler-Volter & Alemania & p. $m$ & alambres & todos \\
\hline 38 & Leoba 1 & Alemania & $\mathrm{m}$ & alambres & todos \\
\hline 39 & Leoba 2 & Alemania & $\mathrm{m} \cdot \mathrm{g}$ & alambres & todos \\
\hline 40 & Lesage & Bélgica & $\mathrm{m}, \mathrm{g}$ & alambres & todos \\
\hline 41 & Macalloy & Gran Bre:aña & p. m. $g$ & bamas & 1 \\
\hline 42 & Magnel-Blaton & Bèlgica & p. m. $g$ & alambres & 2 \\
\hline 43 & Morandi & I:alia & $\mathrm{m}$ & alambres & varios \\
\hline 44 & P.I. & USA & $m$ & alambres & todos \\
\hline 45 & P.S.C. 1 & Gran Bre:aña & p. $m$ & alambres & 1 \\
\hline 48 & P.S.C. 2 & Gran Bre:aña & m. g & cordones & 1 \\
\hline 47 & Polensky \& Zöllner & Alemania & $m$ & alambres & todos \\
\hline 48 & Prescon & USA & $\mathrm{m}$ & alambres & todos \\
\hline 49 & Rheinhausen & Alemania & $\mathrm{m}$ & alambres & todos \\
\hline 50 & Rinaldi & Italia & $m$ & alambres & 1 \\
\hline 51 & Roebling & USA & $g$ & corcones & todos \\
\hline $\begin{array}{l}52 \\
53\end{array}$ & $\begin{array}{l}\text { S.E.E.E. } 1 \\
\text { S.E.E.E. } 2\end{array}$ & $\begin{array}{l}\text { Francia } \\
\text { Francia }\end{array}$ & p.m.g. $G$ & $\begin{array}{l}\text { corcones } \\
\text { cordones }\end{array}$ & $\begin{array}{l}\text { todos } \\
\text { todos }\end{array}$ \\
\hline 54 & Sager \& Woerner & Alemonia & $\mathrm{m}$ & alambres & todos \\
\hline 55 & Stressblock & Gran Bre:aña & g. $G$ & corcones & 1 \\
\hline 56 & Stressiod & USA & $m$ & barras & i \\
\hline $5 \bar{T}$ & Stressteel & USA & $m$ & barras & 1 \\
\hline 58 & Turntable System & URSS & $m$ & alambres & $\mathbf{i}$ \\
\hline 58 & V.S.L. (Losinger) & Suiza & g. $G$ & alambres & todos \\
\hline 60 & Vaessen & Alemania & $\mathrm{m}$ & alambres & todos \\
\hline 61 & Wayss \& Freytag & Alemania & $\mathrm{m}$ & alambres & todos \\
\hline 62 & Wets & Bذilgica & $m$ & alambres & todos \\
\hline 63 & Züblin & Alemaniz & $\mathrm{m} \cdot \mathrm{g}$ & alambres & todos \\
\hline
\end{tabular}

(1) pequena. p: hasta $133.5 \mathrm{kN}$ : media. m: hasta $490 \mathrm{kN}$ : grande. g: hasta $4.450 \mathrm{kN}$ : muy grande. G: >.

(2) Elementos tesados simultáneamente

Figura 16. Patentes de pretensado hasta 1964.

El postesado transversal del acueducto de Alloz se ve, pero ¿y el sistema de postesado longitudinal?

La respuesta está en la figura 22 y en la lectura de referencia. Pero se resalta que es un sistema de postesado longitudinal que se aplica mediante un sistema de puesta en carga transversal.
Estas vigas, que cumplirán 80 años de edad en 2019, son las vigas artesa postesadas más antiguas del mundo.

La metodología de concepción es digna de estudio: cómo se cambia de escala la idea estructural del acueducto de Tempull conservando el concepto básico en el acueducto de Alloz. 


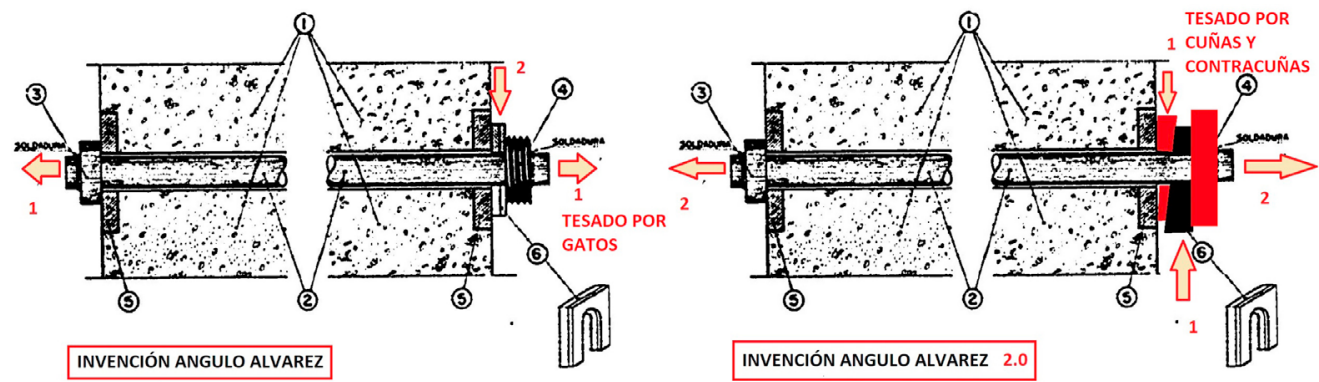

Figura 17. Patente iberoamericana de pretensado anterior a 1957. Versión 2.0 con tesado transversal de cuña y contracuña.

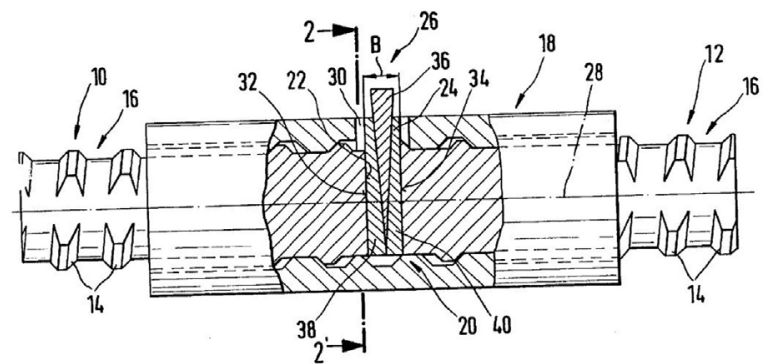

Figura 18. Patente de teutón-luxemburguesa.
La figura 23, del acueducto de Alloz [30] (Archivo Torroja del CHEOPU), recoge la composición gráfica con base en escaneos de fotos y esquemas del archivo Torroja que permiten la explicación gráfica de cómo se realizaba el postesado longitudinal con base en las cargas transversales materializadas mediante el gato hidráulico y el útil de colocación que permite disponer el montante definitivo metálico, momento que recoge la fotografía.

El pretensado se comenzó a desarrollar en España a gran escala gracias, entre otros, a D. Carlos Fernández Casado des-

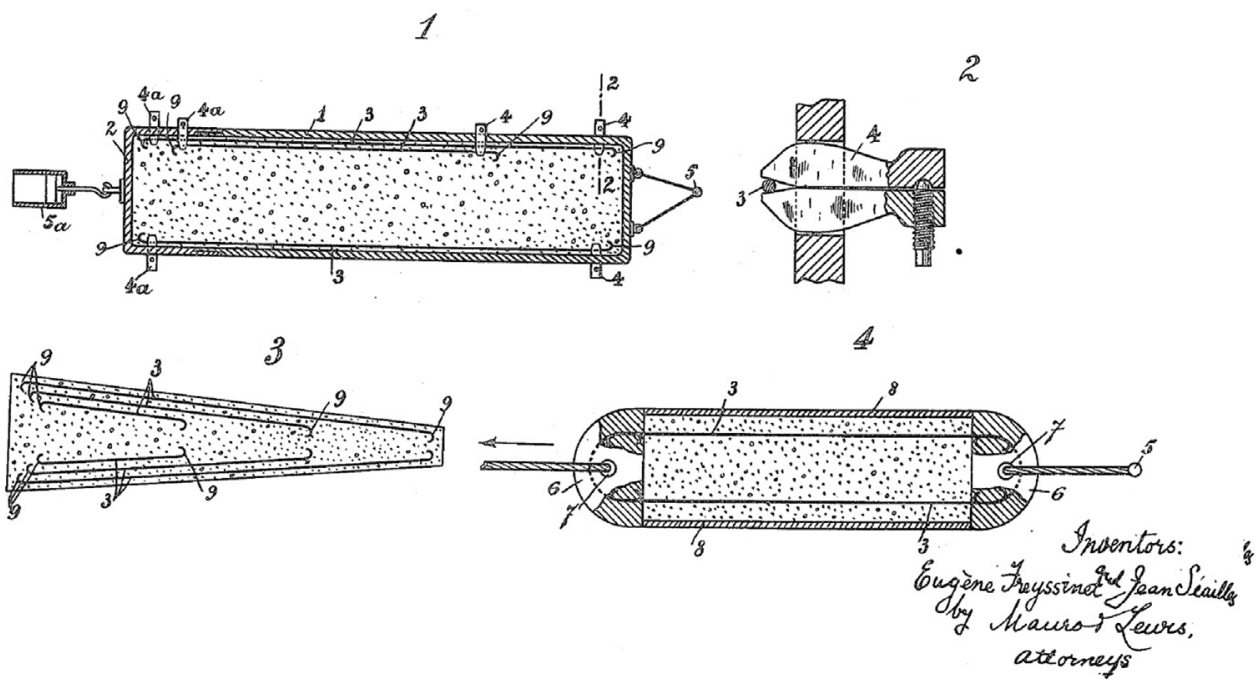

Figura 19. Patente americana de Freyssinet; el ejemplo a seguir.

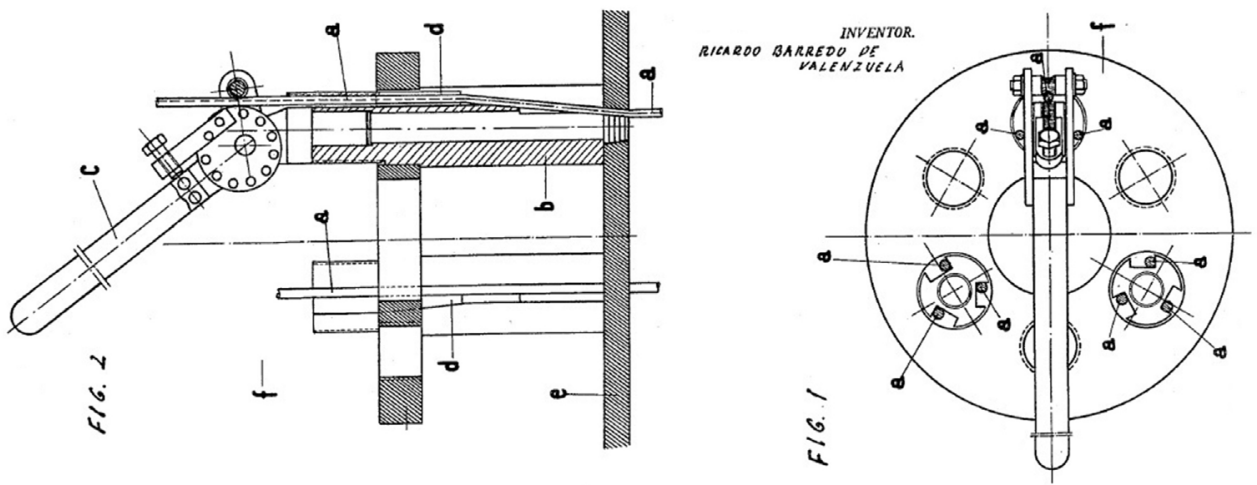

Figura 20. Patente de D. Ricardo Barredo de Valenzuela. 


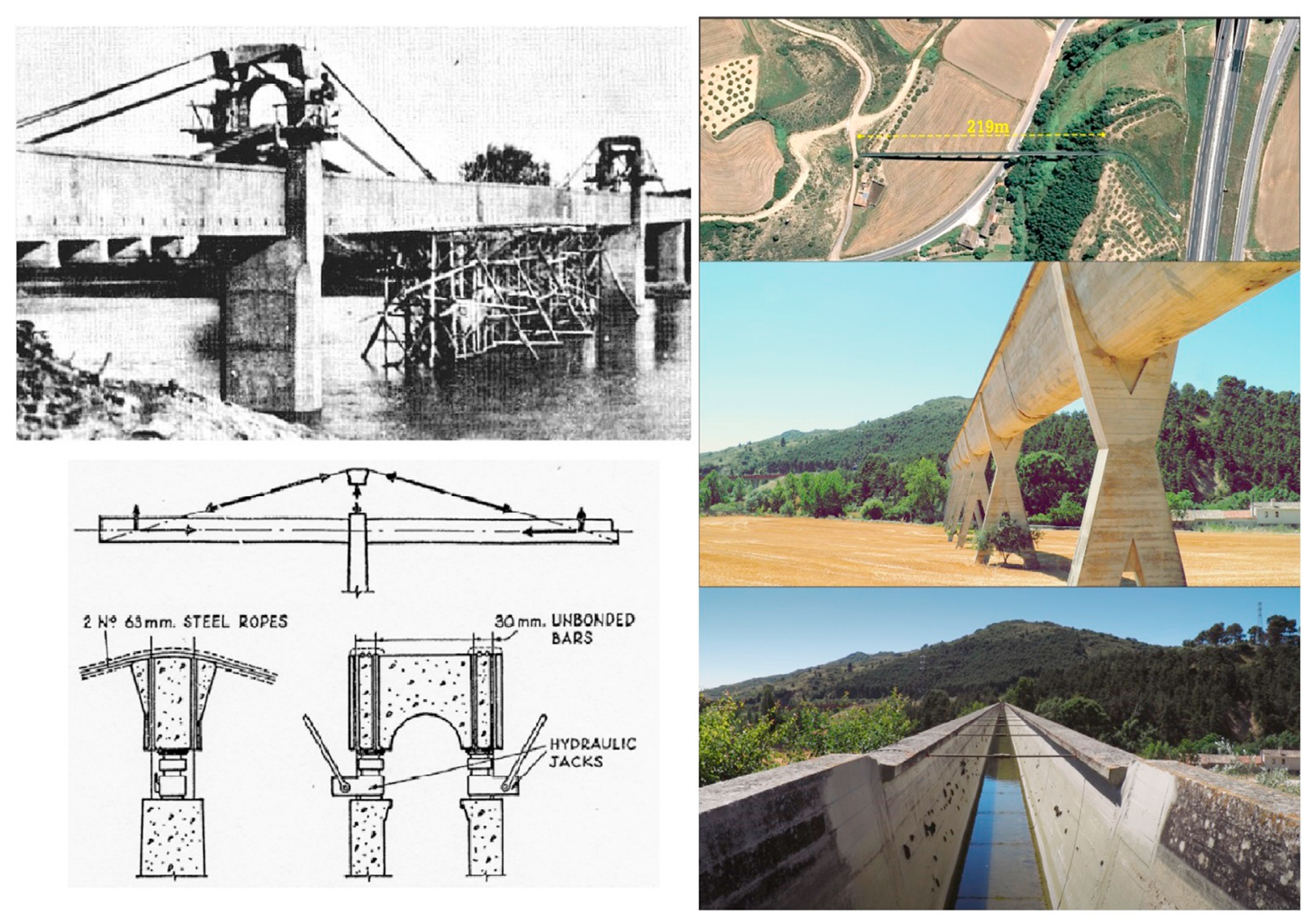

Figura 21. Acueducto de Tempull versus acueducto de Alloz a la derecha.

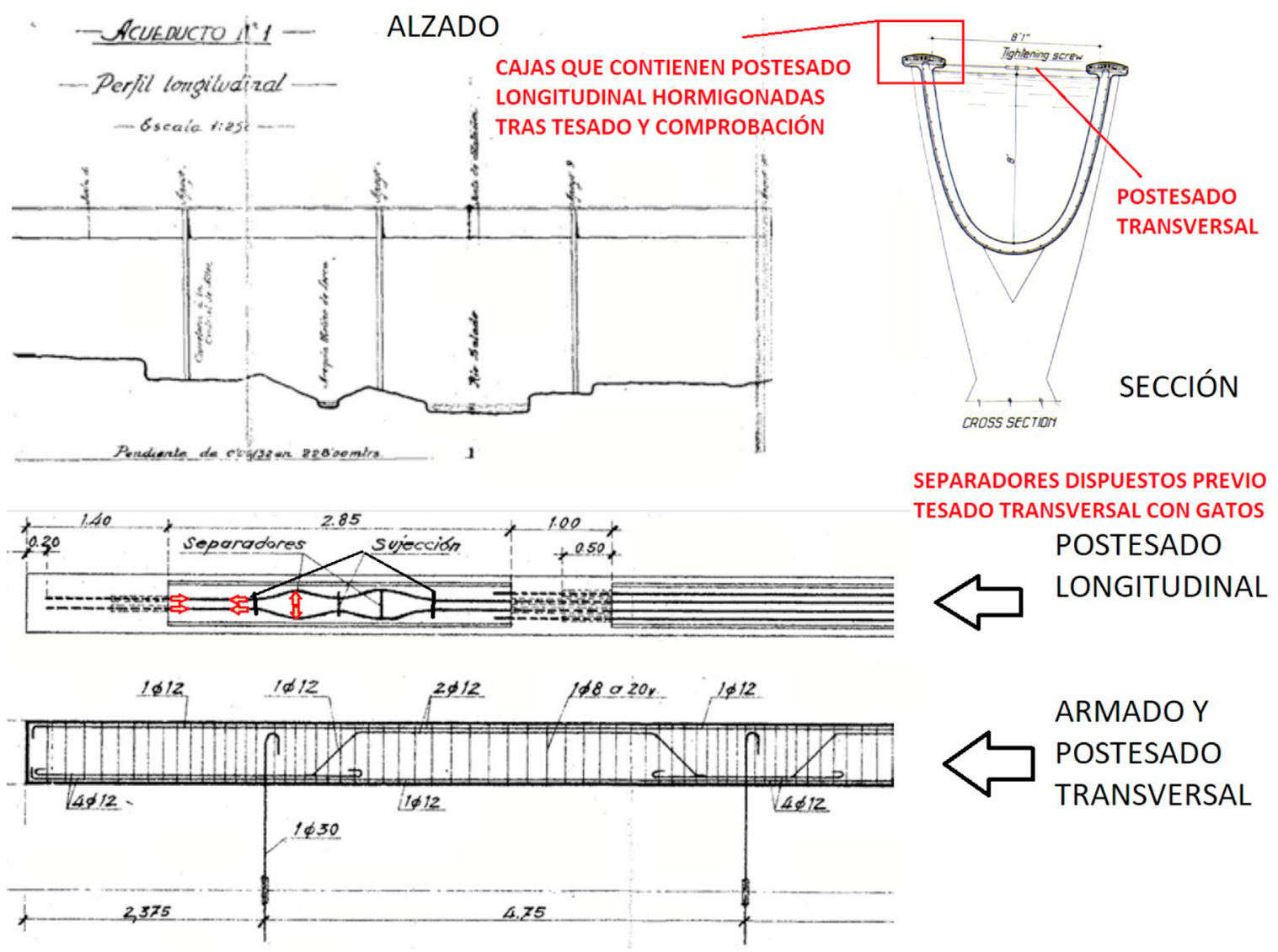

Figura 22. Acueducto de Alloz. Plano original comentado de D. Eduardo Torroja Miret. 

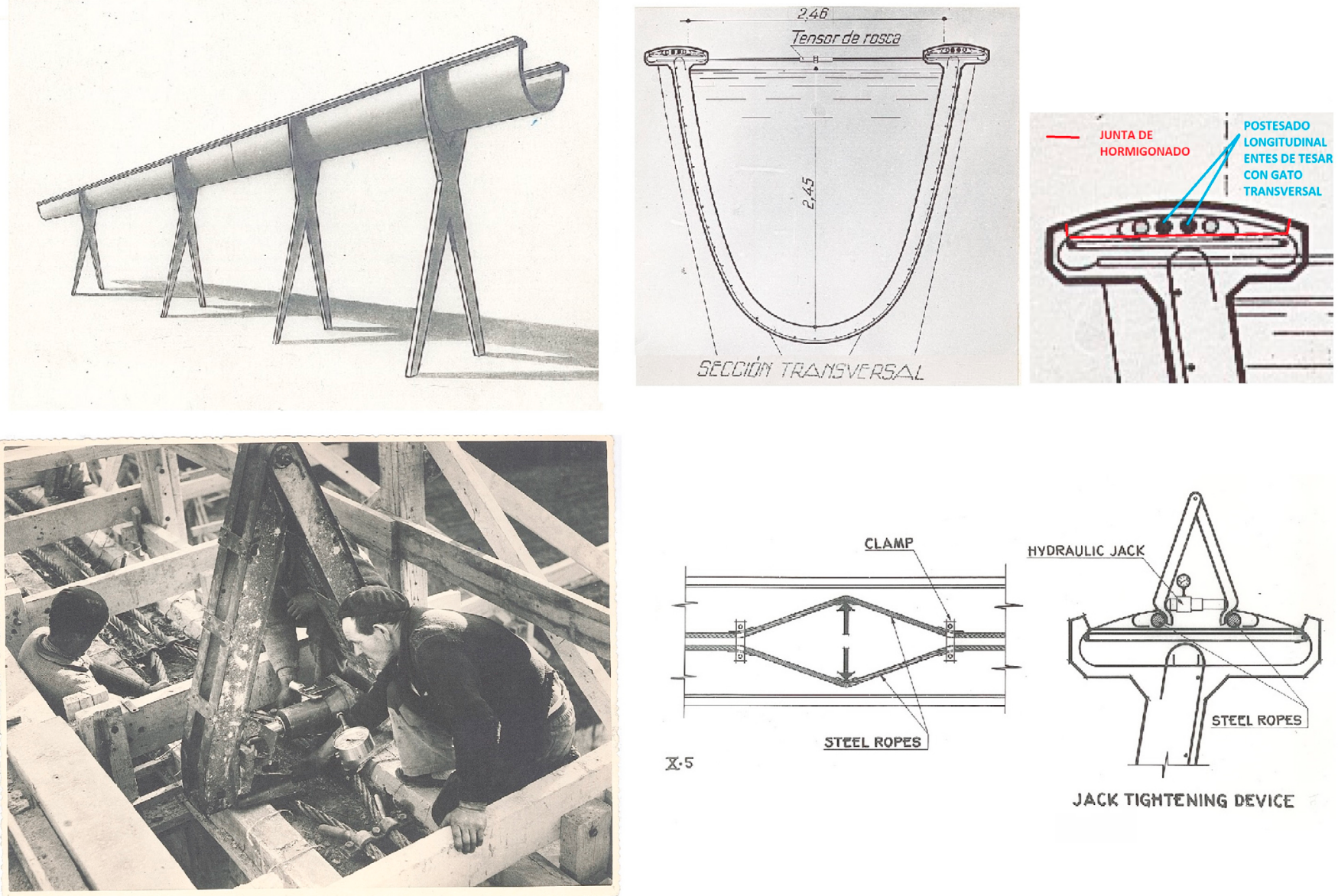

JACK TIGHTENING DEVICE

Figura 23. Acueducto de Alloz. Archivo Torroja del CHEOPU.

de la concepción; desde la prefabricación, el desarrollo en España se debió a D. Francisco Fernández Conde, padre de D. José Antonio Fernández Ordóñez, el autor de la biografía de Freyssinet [34], quien era otro ingeniero innovador como él y desde 1944 explotó la concesión de la patente que le hizo Freyssinet en la empresa PACADAR [35].

\subsection{El sistema cuña-contracuña. Metodología de concepción y esbozo conceptual}

A continuación se presenta muy sucintamente el siguiente sistema de postesado para estructura metálica: el método cuñacontracuña.

Las aplicaciones técnicas que pueden suscitar su uso son, en principio, la rehabilitación de vigas metálicas o mixtas. En estructuras off-shore pueden resultar útiles por poder ser la solución muy económica en algún refuerzo. Es pues un sistema de aplicaciones modestísimas, pero de fácil ejecución.

La idea surge al trabajar en el desarrollo de anclajes a posteriori para la rehabilitación del postesado del puente de Hammersmith para VSL Construction Systems. La concepción intelectual de dichos anclajes es íntegra de D. Carles
Cots Coromina (fig. 24) y comenzó durante el estudio técnico de dicho puente en Londres.

La solución de rehabilitación finalmente ejecutada fue obra de FREYSSINET, con anclajes de hormigón postesado prefabricados; resultó objeto de merecidos galardones en el Reino Unido [36] (fig. 25).

Más tarde se tuvo ocasión de aprovechar todo el trabajo realizado para la obra de Londres mediante un refuerzo con postesado exterior para un forjado de $18 \mathrm{~m}$ de luz; desarrollado junto a D. Gerardo Salazar.

De esta obra de 2015 (fig. 26) se pudo inferir el gran ahorro que se hubiera podido dar en la rehabilitación del puente de Hammersmith con la utilización de esta tipología de anclaje, ya que el manejo de piezas metálicas mucho más livianas en peso hubiera ahorrado mucho tiempo de ejecución.

En esta actuación también surgió el problema del espacio necesario a dejar en el anclaje para la colocación de los gatos y poder tesar longitudinalmente; aunque se dispusieran gatos alevines, el espacio necesario para el tesado era importante. ¿Por qué no plantear un postesado que pueda realizarse desde la mitad de la luz, o incluso en cualquier parte de la luz de la viga? La solución estaba en Torroja, 

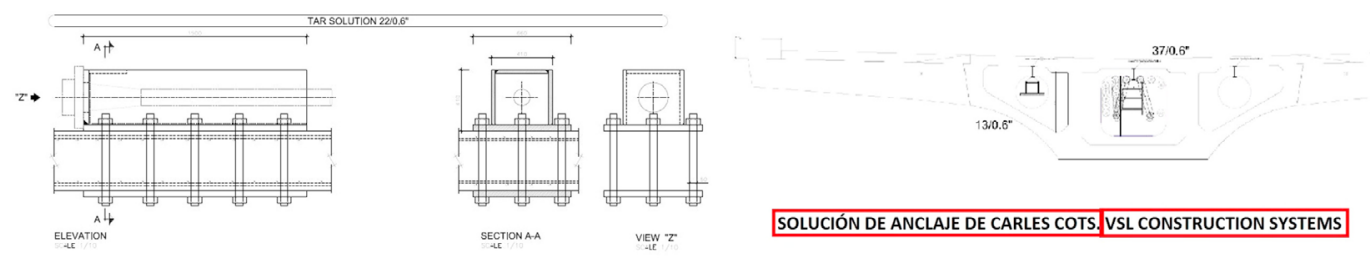

EJEMPLO PARA
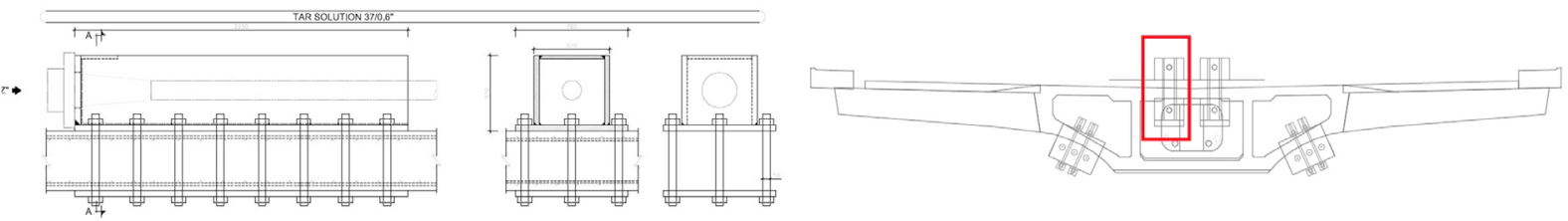

ELEVATION

SECTIONA-A

$\operatorname{VEW}_{-L} \tau$

Figura 24. Solución base de D. Carles Cots para la rehabilitación del puente de Hammersmith. VSL Construction Systems S.A.
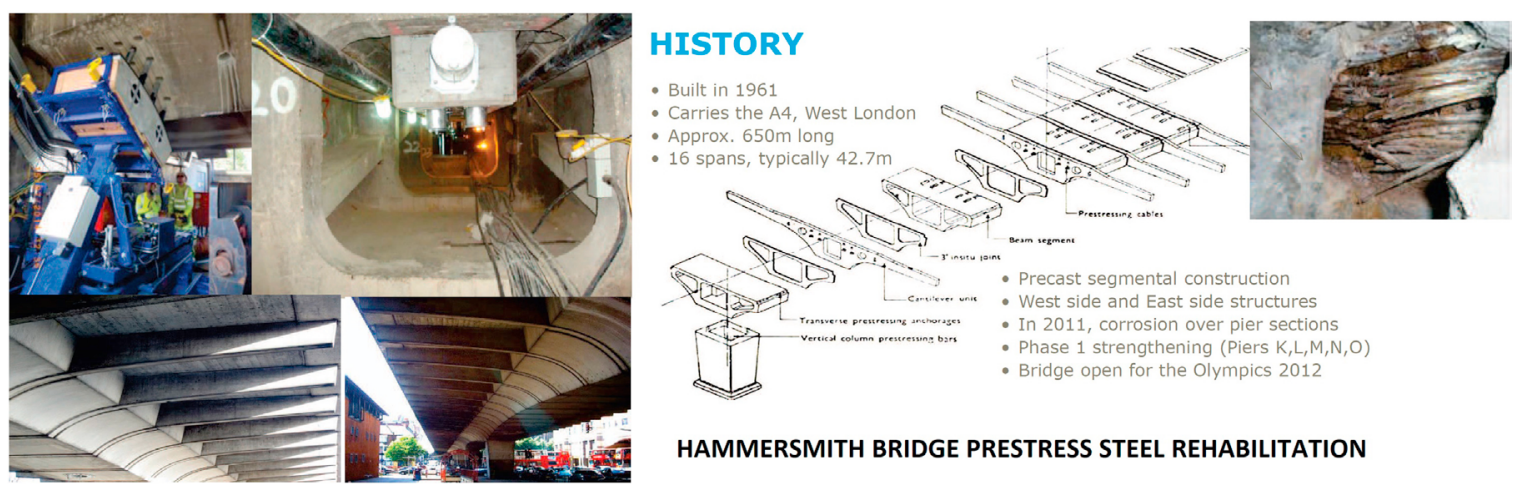

HAMMERSMITH BRIDGE PRESTRESS STEEL REHABILITATION

Figura 25. Solución ejecutada para la rehabilitación del puente de Hammersmith. Ramboll. Freyssinet.
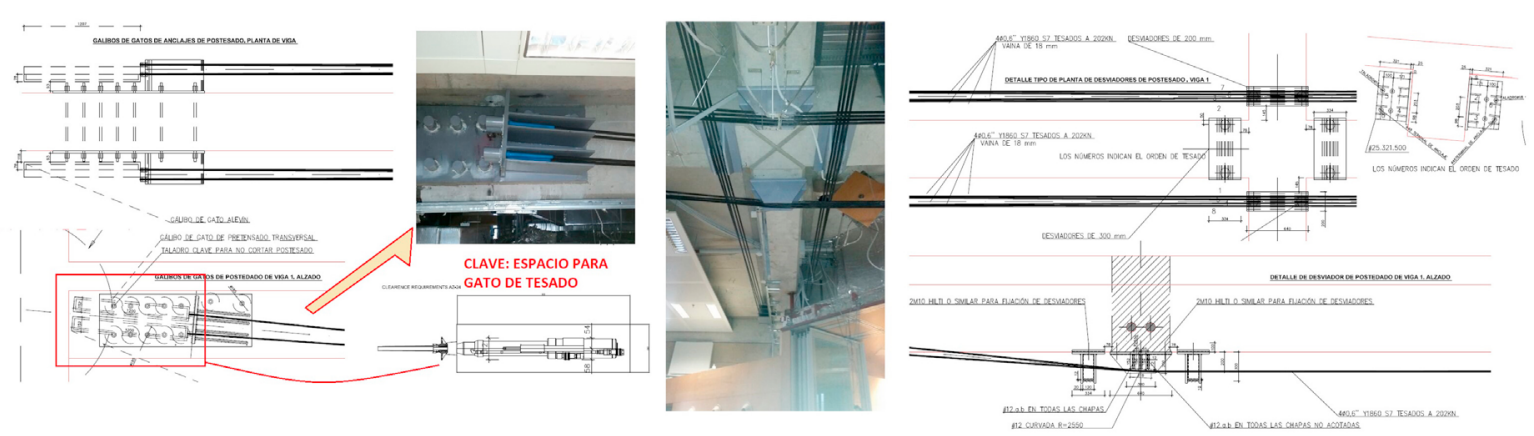

Figura 26. Solución base de D. Carles Cots para anclaje de postesado. VSL Construction Systems S.A.

otra vez: postesa transversalmente para generar el postesado longitudinal.

No es el saber lo que es el postesado (know-), sino que es el cómo ejecutar el postesado de forma repetitiva y sistemática (-how), lo que puede aportar valor añadido.

Para postesar una semi platabanda en toda su longitud contra otra semi platabanda y obtener así la pre-compresión de la platabanda que se refuerza, gracias al trabajo solidario dado por el tornillo pasante, se necesita la cuña a un lado y la contracuña al otro (fig. 27) trabajando juntas. Así se esboza en la figura.
5.

\section{CONCLUSIONES}

Se describe pormenorizadamente un sistema de transferencia de cargas que permite realizar los cortes de soportes estructurales reduciendo costes en medios auxiliares de obra a cambio de mayor esfuerzo en ingeniería.

En el documento se constata además que las tecnologías del postesado están ligadas a la presencia de patentes tecnológicas y/o saber-cómo (know-how) de las empresas que explotan el producto. Se muestran casos reales en que la cultura tecnológica iberoamericana no ha carecido de capacidad de concepción, sino de conservación y fijación empresarial e 

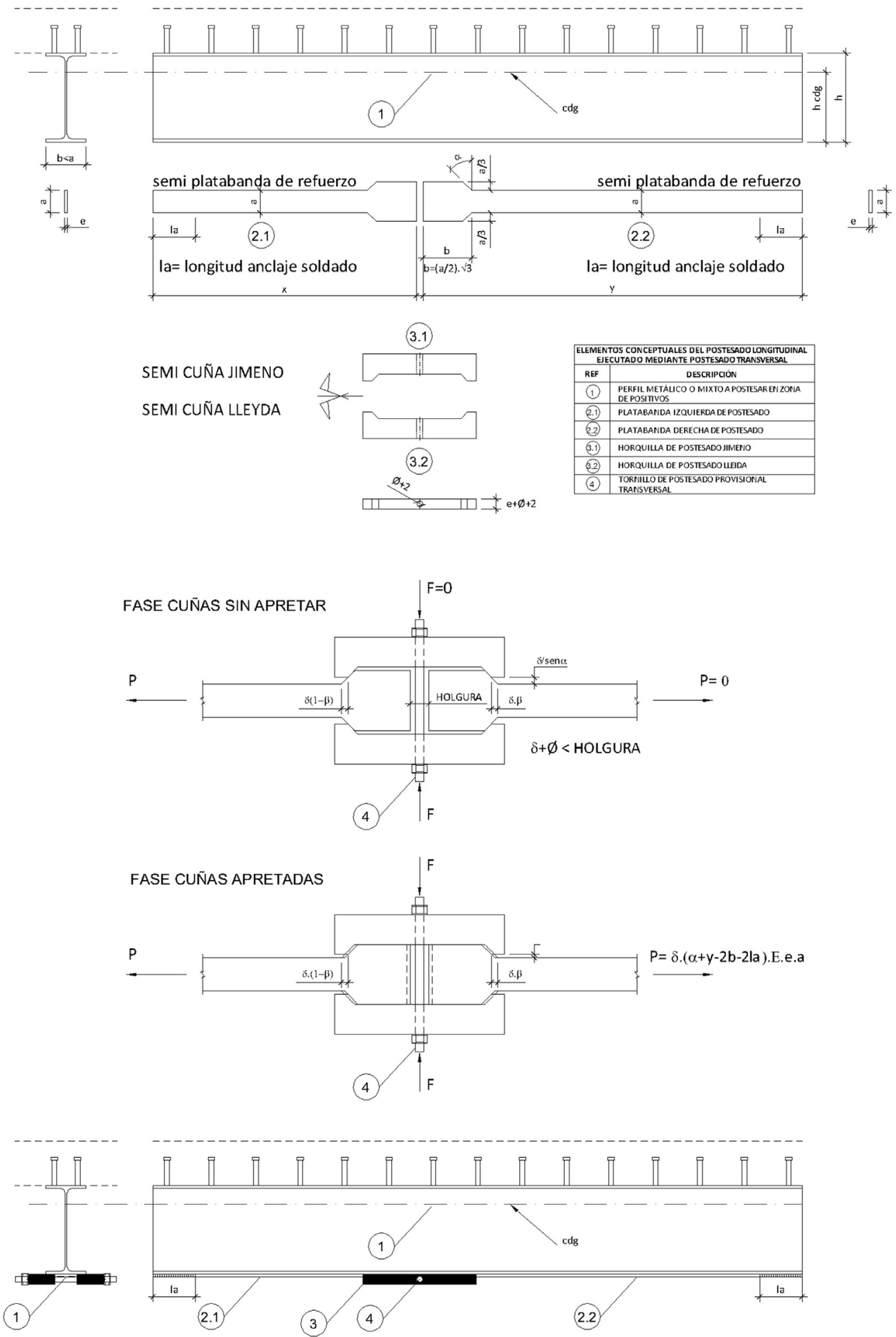

Figura 27. Método de postesado cuña-contracuña.

industrial del saber-cómo para poder repetirlo.

Se propone conceptualmente un sistema de postesado de estructuras metálicas (método cuña-contracuña) basado en el procedimiento de puenteo de cargas para corte de pilar anteriormente descrito.

\section{Bibliografía}

[1] J. Rodríguez Santiago, J.M. Conde-Salazar, Estudio experimental de la puesta en carga de una estructura y el corte del pilar de un edificio de ocho plantas, Hormigón y Acero. (169) (1988) 81-91.

[2] A. González Serrano, Supresión de pilares en una nave, Hormigón y Acero. (178) (1991) 127-133. 
[3] J. Martínez Calzón, I. Ceriani, Estación de Sants en Barcelona — grandes dinteles de apeo para eliminación de soportes entre vías, Congreso de ACHE, Valencia, 2008.

[4] Valladares López J. estructuras postesadas en edificación. Consideraciones estructurales generales, proyectos y obras. En: ACIES; 2012.

[5] Asociación Científico-Técnica del Hormigón Estructural (ACHE). Conservación de aparatos de apoyo, juntas y drenaje en puentes ATC, ACHE, editores; 2011.

[6] Martínez Calzón J, Ladrón de Guevara Méndez G. Ampliaciones de luces de pasos superiores de autopistas existentes. Solución aplicada en la autopista AP-7 (BY-PASS) Valencia. Madrid; 2002.

[7] Martínez Calzón J. Puentes, estructuras, actitudes. Turner; 2006.

[8] Yves Bournand MLB, Adrian Gnagi B, Ayats J, inventores; Device for Anchoring One End of a Stay to a Base. United States. Patente US 6,578,328 B2. 17 June 2003.

[9] Ayats Calsat J. Estado actual del pretensado y tendencias actuales y retos de futuro. 15 de septiembre de 2004.

[10] Dobell C. Patentes relacionadas con el hormigón pretensado. Hormigón y Acero. 1951;(8): 32-40.

[11] Dobell C. Patents and Codes Relating to Prestressed Concret. Journal Proceedings. 1950; 46(5): 713-722.

[12] Goicolea JM. Antonio Angulo (1912), miembro de honor de la Asociación de Ingenieros de Caminos. 11 de abril de 2012

[13] Angulo Álvarez A. Hormigón pretensado, modesta aportación a su técnica. Revista de Obras Públicas. 1957; 1(2904): 167-170.

[14] Reding H, Rehm G, inventores; United States. Patente US6328499 Bl. 11 de diciembre de 2001.

[15] RTVE. Documental sobre Isaac Peral, el inventor del submarino. 1973. Dis- ponible en: http://www.rtve.es/alacarta/videos/ciencia-y-tecnologia-en-rtvees/documental-sobre-isaac-peral-inventor-del-submarino/1628484/.

[16] A. Angulo Álvarez, Un ingeniero de caminos universal. Juan de la Cierva Codorniú, inventor del autogiro, Ingeniería y Territorio. (79) (2007) 58-63.

[17] Santayana G. La vida de la razón o fases del progreso humano.

[18] Damiron JP. Lecciones de filosofía.
[19] Freyssinnet E, Seailles J, inventores. Procédé de fabrication de pièces en béton armé. Fance. Patente FR680547.

[20] Freyssinnet E, inventor; Piece of Reenforced Concrete. United States. Patente US2080074. 11 de mayo de 1937.

[21] FREYSSINET. www. freyssinet.com. 2017. Disponible en: http://www freyssinet.com/freyssinet/wfreyssinetsa sp.nsf/sb/lentreprise. histoire.

[22] BBR. www. bbrnetwork.com. 2017. Disponible en: http://www.bbrnetwork.com/aboutus/history.html.

[23] Warwick B. Hutchins K, inventor; Adjustable Tie Rod Holder. United States. Patente US4124321. 7 de noviembre de 1978.

[24] VSL. www.vsl.com. 2017. Disponible en: http://www.vsl.com/thecompany/history.html.

[25] DYWIDAG. www. dywidag-sistemas.com. 2017. Disponible en: https:// www.dywidag-sistemas.com/empresa/historial/.

[26] Barredo de Valenzuela R, inventor. Tenssioning System. United States. Patente US2820606. 21 de enero de 1958.

[27] Barredo de Valenzuela R, inventor. System of Fixing Cables and Rods Subjected to Stress. United States. Patente US3605202. 20 de septiembre de 1971 .

[28] MeKano4. www.mekano4.com. 2017. Disponible en: http://www.mekano4.com/.

[29] tensainternational. www.tensainternational.com. 2017. Disponible en http://www.tensainternational.com/who-we-are.

[30] Torroja Miret E. ETM-179-001. Salto de Alloz.

[31] Agudelo Zapata JA, Boixader Cambronero D. http://estructurando. net.2013. Disponible en: http://estructurando.net/2013/05/20/descargate-losproyectos-originales-de-las-obras-de-eduardo-torroja-miret/.

[32] Antuña Bernardo J. Estructuras de edificación de Eduardo Torroja Miret.

[33] jbt. PuentéritoPerfecto. 2016 [acceso 19 Dic 2017]. Disponible en: https:// puenteritoperfecto.wordpress.com/2016/03/06/acueducto-alloznavarra/.

[34] Fernández Ordóñez JA. Eugène Freyssinet. Barcelona; 1978.

[35] Esteban García M. Eugène Freyssinet, ingeniero, artesano e inventor. CIMBRA. 2011; p. 44-51.

[36] Clark G. Rehabilitation of PC Bridges in UK - Situation, Strategy, Case Studies. En: EAD16 - Seminar 2016. Munich; 2016. 